\title{
Requirement of Myeloid Cells for Axon Regeneration
}

\author{
Benoit Barrette, Marc-André Hébert, Mohammed Filali, Kathleen Lafortune, Nicolas Vallières, Geneviève Gowing, \\ Jean-Pierre Julien, and Steve Lacroix \\ Department of Anatomy and Physiology, Laval University, Ste-Foy, Québec, Canada G1V 4G2
}

The role of $\mathrm{CD} 11 \mathrm{~b}^{+}$myeloid cells in axonal regeneration was assessed using axonal injury models and CD11b-TK ${ }^{\mathrm{mt}-30}$ mice expressing a mutated HSV-1 thymidine kinase (TK) gene regulated by the myeloid-specific CD11b promoter. Continuous delivery of ganciclovir at a sciatic nerve lesion site greatly decreased the number of granulocytes/inflammatory monocytes and macrophages in the distal stump of $\mathrm{CD} 11 \mathrm{~b}-\mathrm{TK}^{\mathrm{mt}-30}$ mice. Axonal regeneration and locomotor function recovery were severely compromised in ganciclovir-treated CD11b$\mathrm{TK}^{\mathrm{mt}-30}$ mice. This was caused by an unsuitable growth environment rather than an altered regeneration capacity of neurons. In absence of $\mathrm{CD} 11 \mathrm{~b}^{+}$cells, the clearance of inhibitory myelin debris was prevented, neurotrophin synthesis was abolished, and blood vessel formation/maintenance was severely compromised in the sciatic nerve distal stump. Spinal cord-injured axons also failed to regenerate through peripheral nerve grafts in the absence of $\mathrm{CD} 11 \mathrm{~b}^{+}$cells. Therefore, myeloid cells support axonal regeneration and functional recovery by creating a growth-permissive milieu for injured axons.

Key words: nervous system; macrophages; neurotrophins; sciatic nerve; spinal cord injury; angiogenesis

\section{Introduction}

Over recent years, it has become increasingly evident that axon regeneration after neural injury is regulated by many factors. Some studies have suggested that changes in neuronal expression of regeneration-associated genes (RAGs), caused by alterations of intrinsic and/or extrinsic conditions, could account for the inability of neurons to regrow their axons (Plunet et al., 2002). Others have identified and characterized in the adult nervous system proteins that can inhibit axonal growth, such as myelinassociated inhibitors (David and Lacroix, 2003; Yiu and $\mathrm{He}$, 2006). Growth factors, including neurotrophins, and axon guidance molecules have also received their share of attention because they can support cell survival and promote and/or direct axonal growth (Lacroix and Tuszynski, 2000; Harel and Strittmatter, 2006). An interesting observation came from the recent discovery that neurotrophins and axon guidance molecules may also function as angiogenic factors in the injured/diseased nervous system (Carmeliet and Tessier-Lavigne, 2005; Klagsbrun and Eichmann, 2005; Folkman, 2007; Kermani and Hempstead, 2007). Whether the formation of new blood vessels may influence axonal regeneration after injury remains, however, to be investigated. Of particular interest to the present study is the fact that immune cells

\footnotetext{
Received April 4, 2008; revised July 21, 2008; accepted Aug. 10, 2008.

This work was supported by a grant from the Natural Sciences and Engineering Research Council of Canada (S.L.) S.L. is supported by a Career Award from the Rx\&D Health Research Foundation and the Canadian Institutes of Health Research (CIHR). J.-P.J. holds a Canada Research Chair in Neurodegeneration. G.G. is a recipient of a CIHR Doctoral Research Award. All other authors were supported by grants from the CIHR (S.L.). We thank Nadia Fortin, Mélanie Simard, and Renée Paradis for their technical assistance. We acknowledge the work of Julie-Christine Levesque (Bio-Imaging Platform, Research Centre for Infectious Diseases, Centre Hospitalier Université Laval) for her technical assistance for cell imaging. We also thank Marc-André Laniel for his help editing this manuscript.

Correspondence should be addressed to Dr. Steve Lacroix, Centre Hospitalier Université Laval Research Center and Laval University, 2705, Laurier Boulevard, Ste-Foy, Québec, Canada G1V 4G2. E-mail: steve.lacroix@crchul.ulaval.ca.

D0I:10.1523/JNEUROSCI.1447-08.2008

Copyright $\odot 2008$ Society for Neuroscience $\quad 0270-6474 / 08 / 289363-14 \$ 15.00 / 0$
}

may be able to influence all of the above-mentioned cellular responses after injury.

The hypothesis that non-neuronal cells may influence axon regeneration was put forward many years ago by Ramon y Cajal (1991). However, confirmation of this hypothesis only came at the beginning of the 1980s with seminal experiments by David and Aguayo (1981) in which peripheral nerve segments were grafted into the injured CNS. Subsequent studies showed that the presence of viable cells into the grafts was required for axon growth to proceed (for review, see Fu and Gordon, 1997). Interestingly, regeneration of injured axons into acellular peripheral nerve grafts (frozen/thawed grafts) appears to depend on the repopulation of the grafts by migrating/infiltrating cells, because axonal regeneration in these grafts is completely prevented by the administration of a mitosis inhibitor (Hall, 1986). Although Schwann cells were considered to be responsible for promoting axon regeneration in this study, it is likely that other proliferating cells, such as immune cells, may also have been implicated in these effects, especially because the antimitotic drug used did not target Schwann cells specifically. That immune cells may play a crucial role in axonal regeneration only became fully appreciated with the work of Dahlin (1995), who showed that physically preventing cell infiltration into peripheral nerve segments impaired the outgrowth of injured sciatic nerve axons. Yet the exact roles played by immune cells and the mechanisms by which they could regulate regeneration and repair after neural injury are not well defined.

Here, we demonstrate that myeloid cells play a key role in axonal regeneration using various models of axonal injuries and transgenic mice. Selective ablation of $\mathrm{CD} 11 \mathrm{~b}^{+}$cells in vivo using the HSV-1 thymidine kinase (TK)/ganciclovir (GCV) suicide gene system almost completely prevented granulocyte and monocyte/macrophage recruitment and/or proliferation into the injured sciatic nerve. In absence of these immune cells, axonal 
regeneration in the sciatic nerve and recovery of locomotor function were severely compromised with large deficits persisting over several weeks after injury. Careful examination of these mice revealed that $\mathrm{CD} 11 \mathrm{~b}^{+}$cells were responsible for clearance of inhibitory myelin, neurotrophin synthesis, and formation/maintenance of blood vessels into and beyond the lesion site. Moreover, we show that spinal cord-injured (SCI) axons fail to regenerate into peripheral nerve grafts in the absence of CD $11 \mathrm{~b}^{+}$cells. These results show that granulocytes and monocytes/macrophages directly influence axon regeneration by regulating the balance between inhibitory molecules and growth factors.

\section{Materials and Methods \\ Animals}

A total of 452 adult female mice (8-12 weeks of age) were used in this study. Transgenic mice expressing a mutant form of the HSV-1 TK suicide gene under the control of the myeloid-specific CD11b gene promoter, referred to as CD11b-TK ${ }^{\mathrm{mt}-30}$ mice, were generated, reproduced, and genotyped, as described before by Gowing et al. (2006a). Administration of GCV to these mice causes the selective depletion of proliferating $\mathrm{CD}_{1} \mathrm{~b}^{+}$cells. Transgenic mice expressing the yellow fluorescent protein (YFP) marker into a subset of their neurons and axons, thy1YFP-H mice (referred to as YFP mice throughout the text), and those expressing the enhanced green fluorescent protein (EGFP) in Schwann cells, referred to as $\mathrm{S} 100 \beta$-EGFP mice, were purchased from The Jackson Laboratory and genotyped according to the protocol available on their website. For a complete description of these mice, please refer to the studies by Feng et al. (2000) and Zuo et al. (2004). YFP and S100 $\beta$-EGFP mice were crossed with CD11b-TK ${ }^{\mathrm{mt}-30}$ mice for the experiments involving peripheral nerve (PN) grafts and flow cytometry, respectively. NOD/ $\mathrm{CB} 17-\mathrm{Prkdc}^{\text {scid }} / \mathrm{J}$ mice in the NOD/LtSz background and their wild-type counterparts, NOD/ShiLtJ mice, were also purchased from The Jackson Laboratory. NOD/CB17-Prkdc scid/J mice homozygous for the severe combined immune deficiency (scid) spontaneous mutation are characterized by an absence of functional T-cells and B-cells. Mice had ad libitum access to food and water. All surgical procedures were approved by the Laval University Animal Care Committee and followed Canadian Council on Animal Care guidelines.

\section{Cell culture}

Primary Schwann cell and fibroblast cultures derived from sciatic nerves of adult CD11b-TK ${ }^{\mathrm{mt}-30}$ mice and their wild-type littermates were prepared according to established protocols (Morrissey et al., 1991; Weidner et al., 1999). Details are available in the supplemental Methods (available at www.jneurosci.org as supplemental material).

To confirm that the HSV-1 TK ${ }^{\mathrm{mt}-30}$ transgene was expressed specifically by cells of myeloid origin, and not by other cell types in the sciatic nerve, cultures of Schwann cells and fibroblasts obtained from CD11b$\mathrm{TK}^{\mathrm{mt}-30}$ transgenic mice or their wild-type littermates were treated or not with GCV. For this experiment, Schwann cells and fibroblasts were seeded at $2.5 \times 10^{4}$ cells/well and positive control cells (i.e., GL261CMV-TK) at $1 \times 10^{5}$ cells/well in CultureSlides (Falcon; BD Biosciences Discovery Labware) in their respective cell culture medium. Three days later, the medium was changed, GCV at $1 \mu \mathrm{M}$ or PBS was added, and cells were allowed to grow for another $3 \mathrm{~d}$. Cells were then fixed with $4 \%$ paraformaldehyde (PFA) in PBS, pH 7.4, for 20 min and immediately processed for immunofluorescence following our previously described protocol (Pineau and Lacroix, 2007). Details are available in the supplemental Methods (available at www.jneurosci.org as supplemental material).

For quantification of Schwann cells $\left(\mathrm{p} 75^{\mathrm{NTR}+} / \mathrm{S} 100 \beta^{+}\right)$and fibroblasts (fibronectin ${ }^{+} / \mathrm{S} 100 \beta^{-}$), the number of labeled cells was estimated by the optical fractionator method using the Bioquant Nova Prime software (Bioquant Image Analysis). Details are available in the supplemental Methods (available at www.jneurosci.org as supplemental material).

\section{Surgeries and animal treatment}

Sciatic nerve microcrush lesions. Mice were deeply anesthetized with isoflurane and underwent a microcrush lesion of their left sciatic nerve at the midthigh level, following our previously published method (Boivin et al., 2007). As before, the lesion site was marked with a 10-0 Ethilon suture (Ethicon) passed through the epineurium only.

$G C V$ treatment. Mice were treated with four intraperitoneal injections of either saline or GCV (Cytovene; Roche) at $50 \mathrm{mg} / \mathrm{kg}$, starting $12 \mathrm{~h}$ before the lesion followed by injections every $12 \mathrm{~h}$ until the $24 \mathrm{~h}$ time point after lesion. In addition, mice were implanted with miniosmotic pumps (model 2004; Alzet) to continuously deliver saline or GCV at the lesion site $(0.25 \mu \mathrm{l} / \mathrm{h}$ at $10 \mu \mathrm{g} / \mu \mathrm{l}$ for $28 \mathrm{~d})$ throughout the duration of the experiments. For the purpose of the experiment in which we assessed the role of $\mathrm{CD}_{11 \mathrm{~b}^{+}}$cells in angiogenesis/blood vessel integrity after peripheral nerve lesion, mice received bidaily intraperitoneal injections of either saline or GCV at $50 \mathrm{mg} / \mathrm{kg}$ starting $12 \mathrm{~h}$ before the lesion until the end of the experimental protocol (i.e., $7 \mathrm{~d}$ after lesion).

Sciatic-sciatic nerve grafts. To investigate the capacity of peripheral axons to regenerate in the absence of $\mathrm{CD} 11 \mathrm{~b}^{+}$cells, we performed experiments in which pre-degenerated sciatic nerve segments collected from either saline-treated or GCV-treated $\mathrm{YFP}^{-} / \mathrm{TK}^{+}$(i.e., CD11b$\mathrm{TK}^{\mathrm{mt}-30+/-}$ ) and $\mathrm{YFP}^{-} / \mathrm{TK}^{-}$[i.e., wild type (WT) for the CD11b$\mathrm{TK}^{\mathrm{mt}-30}$ transgene] mice were grafted to the sciatic nerve of $\mathrm{YFP}^{+} / \mathrm{TK}^{+}$ and $\mathrm{YFP}^{+} / \mathrm{TK}^{-}$recipient mice, allowing to visualize $\mathrm{YFP}^{+}$axons that have regenerated into grafts (for an example of this, see Fig. 4a). All grafts were allografts and performed under deep isoflurane anesthesia. First, $\mathrm{YFP}^{-} / \mathrm{TK}^{+}$and $\mathrm{YFP}^{-} / \mathrm{TK}^{-}$donor mice underwent sciatic nerve microcrush lesions at midthigh level and treatment with either saline or GCV, as described above. One week later, a 3-mm-long segment of their sciatic nerve distal stump was removed, trimmed of excess epineurial fat in sterile HBSS, and immediately sutured between the sciatic nerve proximal and distal stumps of freshly transected recipient mice (i.e., $\mathrm{YFP}^{+} /$ $\mathrm{TK}^{+}$and $\mathrm{YFP}^{+} / \mathrm{TK}^{-}$mice). Grafts were aligned with the proximal and distal ends of the recipient sciatic nerve and secured using 10-0 Ethilon sutures. Recipient mice were treated with either saline or GCV for the entire duration of the experimental protocol. For this particular experiment, we selected 2 weeks as the optimal survival time after grafting based on recommendations from a previous study by English et al. (2005).

Intraspinal transplantation of sciatic nerve segments. To investigate the capacity of central axons to regenerate in the absence of $\mathrm{CD} 11 \mathrm{~b}^{+}$cells, we performed experiments in which pre-degenerated sciatic nerve grafts collected from either saline-treated or $\mathrm{GCV}$-treated $\mathrm{YFP}^{-} / \mathrm{TK}^{+}$and $\mathrm{YFP}^{-} / \mathrm{TK}^{-}$mice were grafted into the injured spinal cord of $\mathrm{YFP}^{+} / \mathrm{TK}^{+}$ and $\mathrm{YFP}^{+} / \mathrm{TK}^{-}$recipient mice (for an example of this, see Fig. $9 a$ ). Briefly, $\mathrm{YFP}^{-} / \mathrm{TK}^{+}$and $\mathrm{YFP}^{-} / \mathrm{TK}^{-}$mice underwent sciatic nerve microcrush lesions at midthigh level and treatment with either saline or GCV. One week later, pre-degenerated sciatic nerve distal stumps depleted or not in $\mathrm{CD}_{11 \mathrm{~b}^{+}}$cells were isolated, cut into $2 \mathrm{~mm}$ segments, and immediately transplanted into the injured spinal cord of dorsal hemisected $\mathrm{YFP}^{+} / \mathrm{TK}^{+}$and $\mathrm{YFP}^{+} / \mathrm{TK}^{-}$recipient mice. Once again, recipient mice were treated with either saline or GCV for the entire duration of the experimental protocol. SCI mice were killed after 1 week after grafting. Please refer to our previously published protocols for the lesion/ grafting surgery (Lacroix et al., 2002; Vallières et al., 2006).

\section{Tissue processing}

For the experiments involving in situ hybridization (ISH) or ISH combined to immunohistochemistry, mice were overdosed with a mixture of ketamine and xylazine and transcardially perfused with $0.9 \%$ saline solution followed by $4 \% \mathrm{PFA}, \mathrm{pH} 9.5$, in borax buffer. After perfusion with the fixative, brains, sciatic nerves, dorsal root ganglia (DRGs), and spinal cords were dissected out, postfixed for $2 \mathrm{~d}$, and placed overnight in a $4 \%$ PFA-borax $/ 10 \%$ sucrose solution until tissue processing. For the purpose of histological and immunohistochemical labeling, animals were perfused instead with cold PBS followed by $4 \%$ PFA, pH 7.4, in PBS. Sciatic nerves were postfixed for $1 \mathrm{~h}$ only and then placed in a PBS/20\% sucrose solution until sectioning. More details are provided in the supplemental Methods (available at www.jneurosci.org as supplemental material).

\section{ISH}

ISH was performed to detect mRNAs coding for the following molecules: GAP-43, CAP-23, T $\alpha-1$ tubulin, NGF, BDNF, Neurotrophin-3 (NT-3), 
NT-4/5, Tie2, and p $75^{\text {NTR }}$. Radiolabeled cRNA probes were synthesized using full-length cDNAs cloned into expression vectors pCRII-TOPO and the Riboprobe Combination System SP6/T7 (Promega) and T3 RNA polymerase (Promega). Sequences chosen for probe synthesis were selected to match only the intended genes, as verified by BLAST analysis in GenBank. ISH was performed according to a previously described method (Barrette et al., 2007; Pineau and Lacroix, 2007). All sections were prehybridized, hybridized, and posthybridized in parallel to equalize background intensity. A combination of ISH with immunohistochemistry was performed to localize gene expression in individual cells, according to our previously published protocol (Pineau et al., 2006).

\section{Histology and immunohistochemistry}

One series of adjacent sciatic nerve sections was stained with Luxol fast blue (LFB) to identify myelin, following our previously published protocol (Vallières et al., 2006). These sections were used to quantify myelin clearance in the degenerating sciatic nerve distal stump.

Immunoperoxidase labeling was performed following our previously published protocol (Vallières et al., 2006), except that the hydrogen peroxide $\left(\mathrm{H}_{2} \mathrm{O}_{2}\right)$ quenching procedure (to reduce the activity of endogenous peroxidases) was performed with $6 \% \mathrm{H}_{2} \mathrm{O}_{2}$ in methanol for $1 \mathrm{~h}$. All sections were stained in parallel to equalize the background intensity and the peroxidase reaction. Multiple immunofluorescence labeling was performed as described previously (Pineau and Lacroix, 2007). The complete description of the primary antibodies used in this study and their dilution are given in supplemental Table 1 (available at www. jneurosci.org as supplemental material).

To further confirm the clearance of myelin debris and examine the myelin phagocytic activity of macrophages in our experiments, Oil Red O (ORO) staining was combined with CD68 immunofluorescence on the same series of sciatic nerve sections. As previously reported by us and others, ORO staining is highly specific for degenerating myelin and for myelin that has been ingested by macrophages (Ma et al., 2002; Vallières et al., 2006). Immunofluorescence was performed first followed by ORO staining, as previously described (Boivin et al., 2007).

\section{Epon embedding and toluidine blue staining}

For examination of motor and sensory neuron viability after sciatic nerve microcrush lesion in mice depleted in $\mathrm{CD} 11 \mathrm{~b}^{+}$cells, animals were perfused with 4\% PFA, pH 7.4, at $50 \mathrm{~d}$ after lesion. Ipsilateral L5 dorsal and ventral roots were immediately collected, postfixed in $2.5 \%$ glutaraldehyde and $0.5 \%$ PFA in PBS buffer, $\mathrm{pH} 7.4$, for $2 \mathrm{~h}$, postfixed in $2 \%$ osmium tetroxide for another $2 \mathrm{~h}$, and then processed for embedding in Epon following our previously described protocol (Vallières et al., 2006). One-micrometer-thick cross sections of the roots were stained with $1 \%$ toluidine blue for light microscopy.

\section{Quantification of ISH signal and histological and immunohistochemical labeling}

Quantification was performed using the Bioquant Nova Prime image analysis system (Bioquant Image Analysis). Details are available in the supplemental Methods (available at www.jneurosci.org as supplemental material.

\section{Flow cytometry analysis of sciatic nerve Schwann cells}

To address the question of whether depletion of CD11b ${ }^{+}$myeloid cells may have affected Schwann cell function, rather than Schwann cell proliferation, the expression of Galectin-3 in Schwann cells was examined in vivo using flow cytometry. This was done on Schwann cells purified from sciatic nerve distal stump biopsies obtained from mice generated from crossing S100 $\beta$-EGFP with CD11b-TK ${ }^{\mathrm{mt}-30}$ mice. In this experimental setting, Schwann cells were gated based on their expression of $S 100 \beta$ (i.e., GFP) and $\mathrm{p} 75^{\mathrm{NTR}}$. Surface and intracellular expression of Galectin-3 was then examined in Schwann cells collected from S100 $\beta$-EGFP/CD11b$\mathrm{TK}^{\mathrm{mt}-30}$ transgenic mice or their wild-type littermates after treatment with either saline or GCV. More details are available in the supplemental Methods (available at www.jneurosci.org as supplemental material).

\section{Behavioral analysis}

Recovery of locomotor function after sciatic nerve lesion was quantified using the sciatic nerve functional index (SFI), as described previously
(Boivin et al., 2007). This test was performed for all animals preoperatively and every week for 7 weeks after the operation. The SFI was measured using the formula adapted for mice by Inserra et al. (1998). SFI values oscillated around $0 \pm 10$ for noninjured animals and around $-100 \pm 10$ after complete lesion of the sciatic nerve (de Medinaceli et al., 1982). All behavioral analyses were done blind with respect to the identity of the animals.

\section{Statistical analysis}

All statistical evaluations were performed with one- or two-way ANOVA or repeated-measures ANOVA. Post-ANOVA comparisons were made using the Bonferroni test. All statistical analyses were performed using the GraphPad Prism software (GraphPad Software). A value of $p<0.05$ was considered to be statistically significant. Data in graphs are presented as mean \pm SEM.

\section{Results}

The HSV-TK transgene is specifically expressed by cells of myeloid origin in the injured sciatic nerve of CD11b-TK ${ }^{\text {mt-30 }}$ mice

The specificity of expression of the HSV-TK transgene was first assessed in vitro using primary cultures of Schwann cells and fibroblasts derived from sciatic nerves of adult CD11b-TK ${ }^{\mathrm{mt}-30}$ transgenic mice and wild-type littermates. First, we established that Schwann cell and fibroblast cultures were pure $(>98 \%$ purity) based on multiple immunofluorescence labeling using cellspecific markers (supplemental Fig. $1 a-d$, available at www. jneurosci.org as supplemental material). Cells were then treated with either GCV or PBS for $3 \mathrm{~d}$ and counted to verify whether treatment induced cell death (supplemental Fig. 1e, available at www.jneurosci.org as supplemental material). Cells from a mouse glioma cell line, GL261, transduced with a lentiviral vector expressing the HSV-TK construction under the control of the CMV promoter (GL261-CMV-TK) were used as positive control cells. As demonstrated in supplemental Figure 1e (available at www.jneurosci.org as supplemental material), the addition of GCV to the culture medium led to the killing of almost all GL261CMV-TK control cells, but had no effect on the survival of both Schwann cells and fibroblasts. This confirmed the lack of ectopic expression of the HSV-TK transgene in these cells.

It was imperative to obtain in vivo evidence that GCV treatment did not ablate proliferating Schwann cells in our CD11b$\mathrm{TK}^{\mathrm{mt}-30}$ transgenic mice, because these cells have been long recognized to play an indispensable role in promoting peripheral nerve regeneration and repair after injury (Fu and Gordon, 1997). Thus, we examined whether there was a decrease of Schwann cells after a sciatic nerve microcrush lesion in GCVtreated CD11b-TK ${ }^{\mathrm{mt}-30}$. For this, transgenic mice and their wildtype littermates received intraperitoneal injections (twice a day for $2 \mathrm{~d}$ ) of either GCV or saline plus continuous delivery of the drugs at the lesion site using Alzet miniosmotic pumps. Schwann cells were visualized through detection of the Schwann cell marker, $\mathrm{p} 75^{\mathrm{NTR}}$, in peripheral nerve preparations using ISH. As shown in supplemental Figure $2 a$ (available at www.jneurosci.org as supplemental material), the levels of $\mathrm{p} 75^{\mathrm{NTR}}$ mRNA signal at various distances from the site of sciatic nerve lesion did not statistically differ between groups at $7 \mathrm{~d}$ after lesion.

\section{GCV administration to CD11b-TK ${ }^{\mathrm{mt}-30}$ transgenic mice results in the depletion of granulocytes, monocytes, and macrophages in the sciatic nerve after injury}

To identify the populations of myeloid cells that were depleted in GCV-treated CD11b-TK ${ }^{\mathrm{mt}-30}$ transgenic mice, immunolabeling was performed on tissue sections prepared from injured sciatic 
nerves. Macrophages, granulocytes/inflammatory monocytes, T-cells, and B-cells were identified by immunolabeling against CD68, Gr-1, CD3, and CD45R/ B220, respectively, and cells were counted using stereological methods at various distances distal to the lesion site. At $7 \mathrm{~d}$ after lesion, the number of $\mathrm{CD} 68^{+}$and $\mathrm{Gr}-1^{+}$ cells was reduced by 89 and $98 \%$, respectively, in the sciatic nerve distal stump of GCV-treated CD11b-TK ${ }^{\text {mt-30 }}$ transgenic mice compared with control groups (Fig. $1 a-f)$. The continuous delivery of GCV at the lesion site was also associated with a slight but significant decrease in the number of $\mathrm{CD} 8^{+}$macrophages and $\mathrm{Gr}-1^{+}$ granulocytes/inflammatory monocytes in the sciatic nerve distal stump of WT mice. This finding is consistent with reported cases of patients developing granulocytopenia during treatment with GCV, also know as Cytovene (for more information, please consult the product information form available on the Roche Pharmaceuticals website). In contrast, B- and T-cell counts in the injured sciatic nerve were essentially unaltered, except at the lesion site at which a small but statistically significant difference in T-cell numbers was detected between GCV-treated and saline-treated CD11b-TK ${ }^{\mathrm{mt}-30}$ mice (Fig. 1g,h). This finding, which is well in line with results published in a previous study using a similar transgenic mouse model (Heppner et al., 2005), indicates that GCV treatment in CD11b-TK ${ }^{\mathrm{mt}-30}$ mice had limited effects on T- and B-cell number and that lymphocyte recruitment into the injured peripheral nerve did not depend on chemokines/ cytokines released by granulocytes, monocytes, and macrophages or the physical presence of these cells.

\section{Recovery of sciatic nerve functions is} severely compromised in mice depleted in $\mathrm{CD}_{11 \mathrm{~b}}{ }^{+}$myeloid cells

To investigate whether functional recovery would be affected by the absence of $\mathrm{CD}_{11 \mathrm{~b}}{ }^{+}$cells in the context of neural injury, hindlimb motor and sensory function was assessed after sciatic nerve injury using the SFI (Fig. 2). Results showed no statistically significant difference in the preoperative SFI values among the four different groups included in this experiment. However, GCV treatment in sciatic nerve-injured CD11b-TK ${ }^{\mathrm{mt}-30}$ transgenic mice resulted in large deficits in recovery of sciatic nerve functions. When compared with all other groups, statistical significance for SFI values of GCV-treated CD11b-TK ${ }^{\mathrm{mt}-30}$ mice was reached at 14, 21, 28, 35, 42, and $49 \mathrm{~d}$ after lesion (Fig. 2a). Even at $49 \mathrm{~d}$, the latest time point analyzed in this study, GCV-treated transgenic mice were unable to stand on the plantar surface of their toes (Fig. $2 c-e$ ), indicating severe neurological deficits in
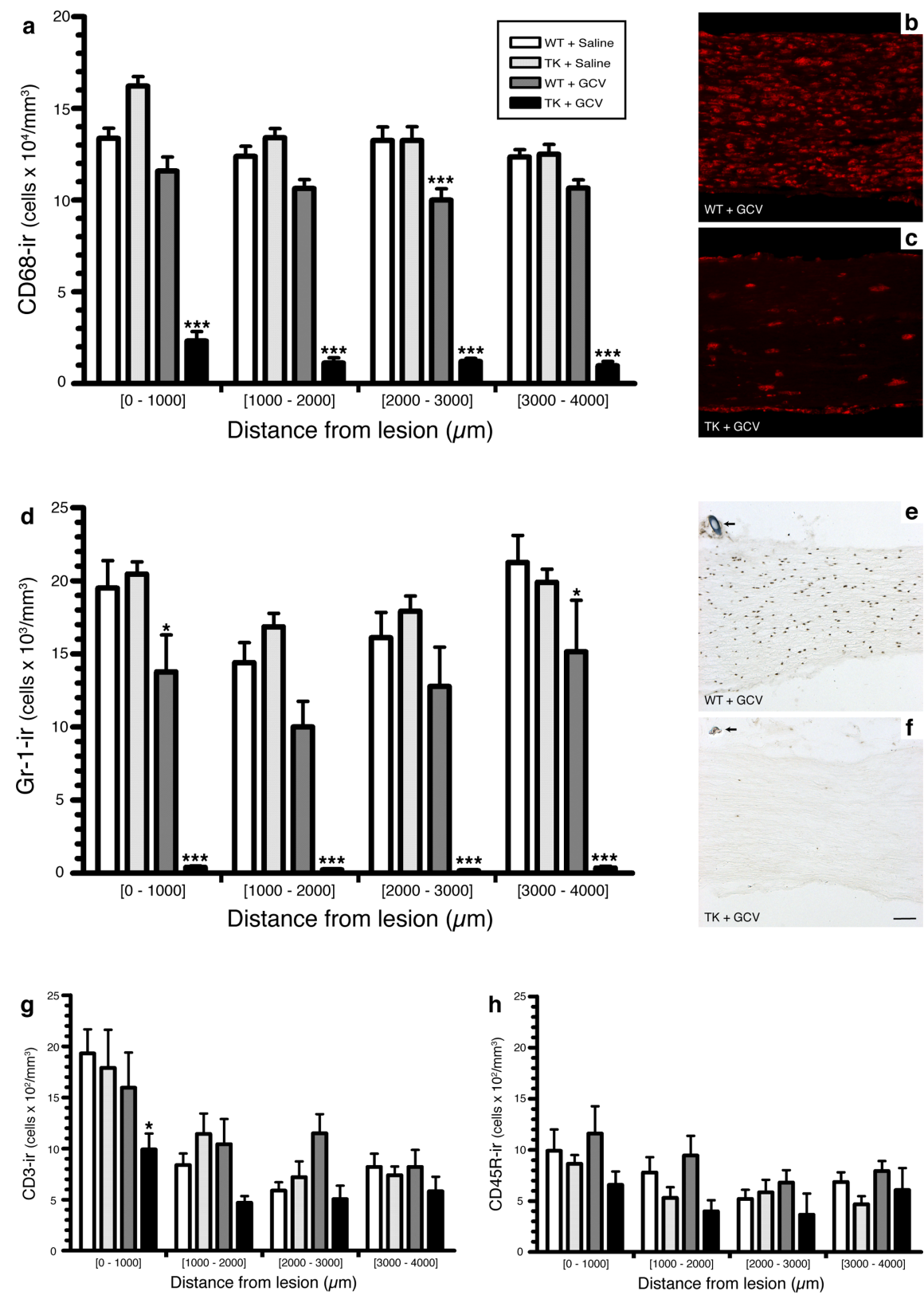

Figure 1. Treatment of CD11b-TK ${ }^{\mathrm{mt}-30}$ (TK) transgenic mice with $\mathrm{GCV}$ results in the almost complete depletion of CD68 ${ }^{+}$ macrophages and $\mathrm{Gr}-1^{+}$granulocytes/inflammatory monocytes in the injured sciatic nerve. $\boldsymbol{a}, \boldsymbol{d}, \boldsymbol{g}, \boldsymbol{h}$, Quantification of the number of CD68-immunoreactive (ir) macrophages, Gr-1-ir granulocytes/inflammatory monocytes, CD3-ir T-cells, and CD45R-ir B-cells in the sciatic nerve distal stump of TK and WT mice at $7 \mathrm{~d}$ after lesion in response to either $\mathrm{GCV}$ or saline treatment $(n=8$ per group). Notably, a 89 and $98 \%$ reduction in the number of $\mathrm{CD}_{68}{ }^{+}$macrophages and $\mathrm{Gr}-1^{+}$granulocytes/inflammatory monocytes, respectively, was observed in the nerve distal stump of GCV-treated TK mice compared with saline-treated TK and WT mice at $7 \mathrm{~d}$ after lesion. $\boldsymbol{b}, \boldsymbol{c}, \boldsymbol{e}, \boldsymbol{f}$, Representative photomicrographs showing $\operatorname{CD68}(\boldsymbol{b}, \boldsymbol{c})$ and $\mathrm{Gr}-1(\boldsymbol{e}, \boldsymbol{f})$ immunostaining in the sciatic nerve distal stump of WT and TK mice treated with GCV at $7 \mathrm{~d}$ after lesion. The arrows point to the 10-0 suture node indicating the site of lesion $(\boldsymbol{e}, \boldsymbol{f})$. All data are expressed as mean \pm SEM. ${ }^{*{ }^{*}} p<0.001$ and ${ }^{*} p<0.05$ compared with respective control groups. Scale bar: (in $\boldsymbol{f}) \boldsymbol{b}, \boldsymbol{c}, \boldsymbol{e}, \boldsymbol{f}, 80 \mu \mathrm{m}$.

these mice. Instead, they stood on their heels and curled dorsal surface of their paws, whereas saline-treated WT animals subjected to a lesion of their left sciatic nerve looked normal at the same time point. Notably, GCV-treated WT animals exhibited significant locomotor deficits compared with saline-treated WT and transgenic mice at 21 and $28 \mathrm{~d}$ after lesion. We explain these results by the fact that continuous delivery GCV at the lesion site was associated with a slight but significant decrease in white blood cell count in the sciatic nerve distal stump of WT animals. 
a

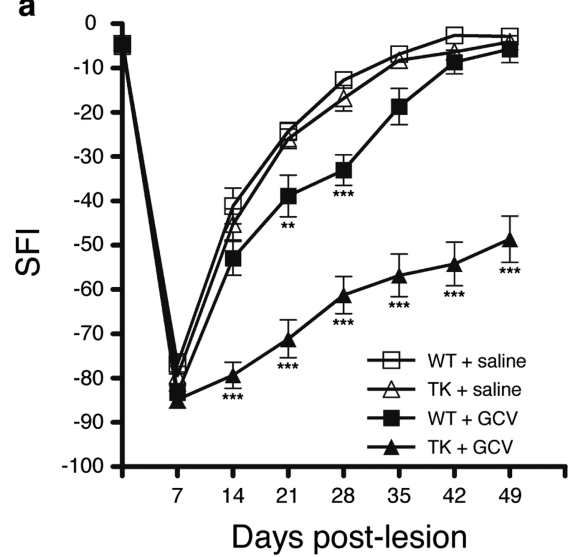

b

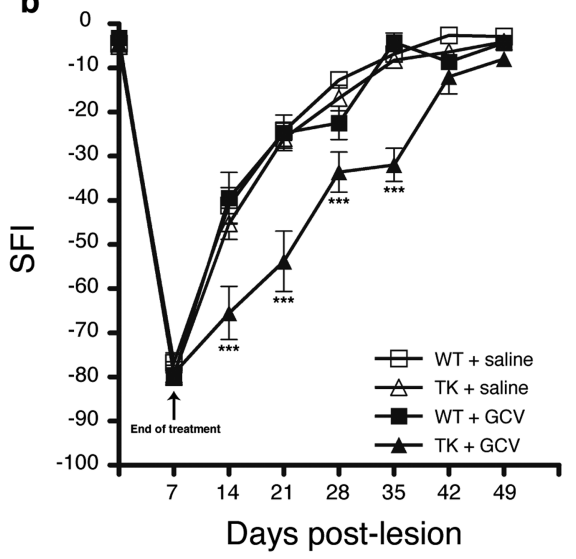

Peripheral nerve axon regeneration is compromised in mice depleted in $\mathrm{CD}_{11 \mathrm{~b}}{ }^{+}$cells

We thus tested whether axonal regeneration was compromised in the absence of $\mathrm{CD} 11 \mathrm{~b}^{+}$cells. For this, we took advantage of transgenic mice that were generated from breeding thy1-YFP-H mice (that express the YFP marker in a subset of their neurons and axons) with CD11b-TK ${ }^{\mathrm{mt}-30}$ mice and quantified the total number of $\mathrm{YFP}^{+}$sciatic nerve axons that had regenerated into $\mathrm{YFP}^{-}$peripheral nerve allografts depleted or not in $\mathrm{CD}_{11 \mathrm{~b}}{ }^{+}$cells. A representative example of the regeneration of $\mathrm{YFP}^{+}$sciatic nerve axons into a graft taken from a saline-treated $\mathrm{TK}^{+} / \mathrm{YFP}^{-}$ mouse at 2 weeks after lesion/grafting is presented in Figure 4, $a$ and $b$. Proximal to the graft at 2 weeks after surgery, no statistically significant difference in the count of $\mathrm{YFP}^{+}$axons was found between the four different groups included in this experiment (Fig. 4c). However, the situation within the graft differed drastically among the groups, because peripheral axons almost completely failed to regenerate in the absence of $\mathrm{CD}_{11 \mathrm{~b}^{+}}$cells. The following axonal numbers $( \pm$ SEM) were counted at predetermined distances within peripheral nerve grafts from GCV-treated CD11b-TK ${ }^{\mathrm{mt}-30}$ mice: $500 \mu \mathrm{m}, 3.7 \pm 1.2$ axons; $1000 \mu \mathrm{m}, 3.0 \pm 0.9$ axons; 1500 $\mu \mathrm{m}, 2.3 \pm 0.8$ axons; and $2000 \mu \mathrm{m}, 1.3 \pm$ 0.8 axons. In all other groups, average

When miniosmotic pumps used to continuously deliver GCV at the lesion site were removed after 1 week after injury of treatment, CD11b-TK ${ }^{\mathrm{mt}-30}$ mice recovered sciatic functions similar to control animals after $6-7$ weeks (Fig. $2 b$ ). This represents a delay of $\sim 1-2$ weeks compared with the typical time course of recovery seen in control mice. Our interpretation of the latter result is that nerve regeneration and repair may have started to proceed as soon as $\mathrm{CD} 11 \mathrm{~b}^{+}$myeloid cells were allowed to proliferate and invade the injured sciatic nerve.

\section{Myeloid cells are not required for survival of axotomized sciatic motor and sensory neurons}

We next asked whether the long-term deficits described above could have been caused by the death of axotomized neurons, because $\mathrm{CD} 11 \mathrm{~b}^{+}$cells could have produced or affected the release of factors that are critical for neuronal survival after injury. To test this possibility, we analyzed the viability of motor and sensory neurons at $50 \mathrm{~d}$ after sciatic axotomy. Results showed that $<2.5 \%$ of all L5 dorsal root ganglion neurons and spinal cord motor neurons projecting into the sciatic nerve had died from the microcrush lesion at $50 \mathrm{~d}$ after injury (data not shown). As demonstrated in Figure 3, neuronal viability did not differ between GCV-treated CD11b-TK ${ }^{\mathrm{mt}-30}$ transgenic mice and control mice at $50 \mathrm{~d}$. These data suggest that the severe and persistent neurological deficits observed in GCV-treated CD11b-TK ${ }^{\mathrm{mt}-30}$ transgenic mice after peripheral nerve injury are not the result of neuronal cell loss, leaving axonal regeneration failure as the most likely explanation. counts of $\mathrm{YFP}^{+}$axons within grafts varied between $45.5 \pm 8.1$ and $61.0 \pm 5.4$ axons at $500 \mu \mathrm{m}, 37.0 \pm 2.8$ and $55.3 \pm 6.2$ axons at $1000 \mu \mathrm{m}, 31.0 \pm 2.9$ and $43.1 \pm 3.3$ axons at $1500 \mu \mathrm{m}$, and $16.8 \pm 3.1$ and $36.6 \pm 3.6$ axons at $2000 \mu \mathrm{m}$. The difference in axonal counts between GCV-treated $\mathrm{TK}^{+}$grafts (these grafts were used to repair the sciatic nerve of $\mathrm{TK}^{+} / \mathrm{YFP}^{+}$recipient mice) and grafts from other groups is significant for all distances analyzed (two-way repeated-measures ANOVA, $p<0.001$ ). Together with our previous finding that sciatic nerve function recovery is severely compromised in GCV-treated CD11b-TK ${ }^{\mathrm{mt}-30}$ mice, these results indicate that myeloid cells are essential for peripheral axon regeneration.

Neuronal cell bodies of axotomized sciatic nerve axons react normally to injury by overexpressing RAGs even in the absence of myeloid cells

We then investigated some of the mechanisms that could be used by $\mathrm{CD} 11 \mathrm{~b}^{+}$myeloid cells to promote axonal regeneration. One likely theory was that $\mathrm{CD} 11 \mathrm{~b}^{+}$cells may somehow alter the intrinsic capacity of neuronal cell bodies to regenerate. Using ISH, we therefore studied the expression of RAGs such as GAP-43, CAP-23, and T $\alpha-1$ tubulin in cell bodies of axotomized motor and sensory neurons projecting through the sciatic nerve. These three RAGs were chosen based on previous studies that showed that the expression of these particular genes reflected the intrinsic capacity of neurons to regenerate their axons [these studies are summarized in the review article by Plunet et al. (2002)]. For this experiment, mice were killed at $7 \mathrm{~d}$ after lesion. This time point 


\section{Ventral root (ipsilateral)}

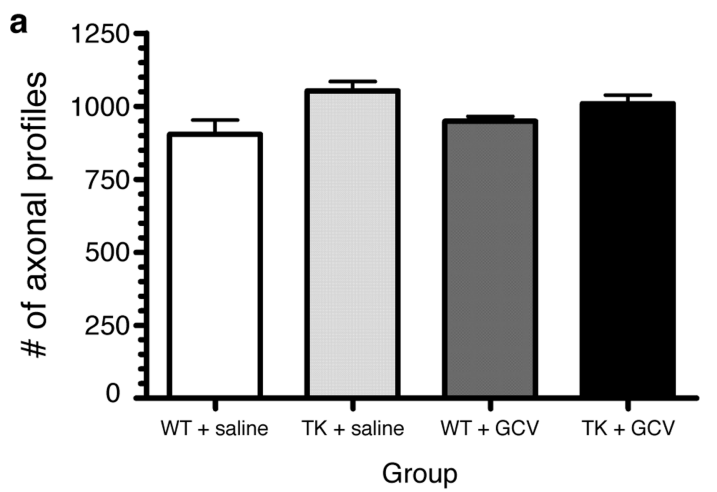

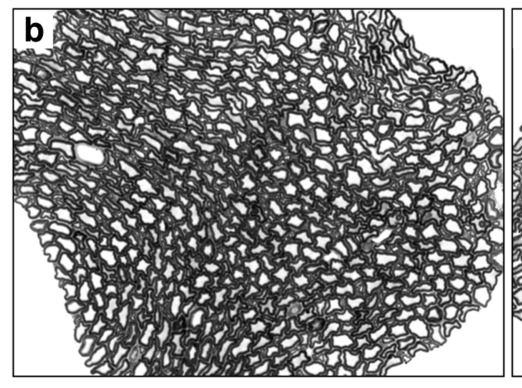

$\mathrm{WT}+\mathrm{GCV}$

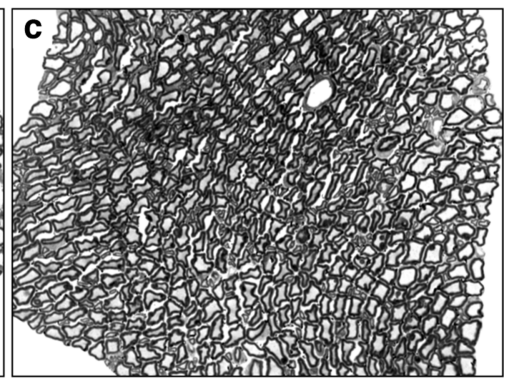

$\mathrm{TK}+\mathrm{GCV}$

\section{Dorsal root (ipsilateral)}
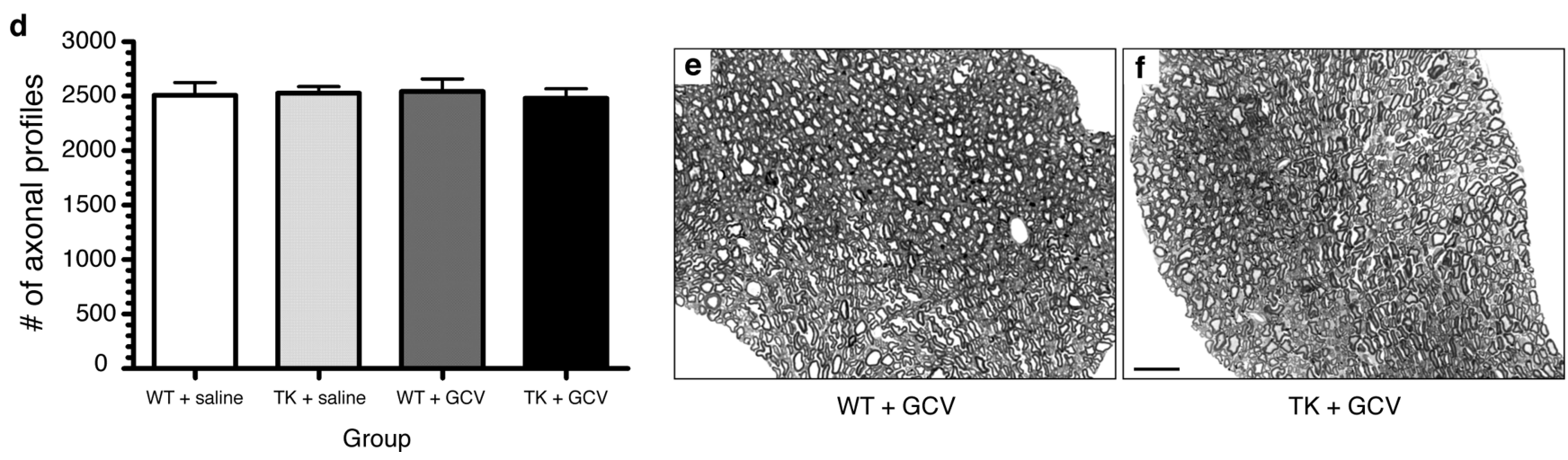

Figure 3. Depletion of $\mathrm{CD} 11 \mathrm{~b}^{+}$cells does not lead to death of axotomized neurons. $\boldsymbol{a}, \boldsymbol{d}$, Counts of axonal profiles in Epon-embedded $\mathrm{L} 5$ ventral and dorsal roots at $50 \mathrm{~d}$ after lesion revealed that differences in functional recovery in CD11b-TK ${ }^{\mathrm{mt}-30}$ (TK) transgenic mice compared with WT are not caused by the loss of motor or sensory neurons. Error bars indicate SEM. $\boldsymbol{b}, \boldsymbol{c}, \boldsymbol{e}, \boldsymbol{f}$, Photomicrographs showing toluidine blue staining of $L 5$ ventral $(\boldsymbol{b}, \boldsymbol{c})$ and dorsal $(\boldsymbol{e}, \boldsymbol{f})$ roots ipsilateral to the lesion. Representative cross sections were taken from $\mathrm{GCV}$-treated WT and TK mice. Scale bar: (in f) $\boldsymbol{b}, \boldsymbol{c}, \boldsymbol{e}, \boldsymbol{f}, 12.5 \mu \mathrm{m}$.

was selected based on a time course study that demonstrated maximal expression between 3 and $7 \mathrm{~d}$ (data not shown). As shown in Figure 5, cell bodies from motor neurons projecting through the sciatic nerve appeared to react normally to the absence of CD11b ${ }^{+}$cells by overexpressing GAP-43, CAP-23, and T $\alpha$-1 tubulin mRNAs (Fig. 5). Similarly, L5 DRG sensory neurons were also found to overexpress these RAGs after injury and mRNA levels remained similar between all groups at $7 \mathrm{~d}$ (data not shown). Obviously, these results do not exclude the possibility that expression of these or other RAG genes was modulated in cell bodies of axotomized neurons at other times after injury. Nevertheless, they do suggest that $\mathrm{CD}_{1} 1 \mathrm{~b}^{+}$myeloid cells modulate axonal regeneration by directly influencing growth cone dynamics through the creation of a more favorable growth environment, having little or no detectable effects at the perikaryon level.

\section{Myeloid cells are essential for the clearance of inhibitory myelin debris after peripheral nerve injury}

One way by which myeloid cells may create a more permissive environment for axon regeneration is by clearing inhibitory myelin debris during wallerian degeneration. We therefore investigated whether clearance of myelin debris would be compromised in the absence of CD $11 b^{+}$cells. Quantification of LFB staining, a marker of myelin, in the sciatic nerve distal stump revealed that the load of myelin debris was $>200 \%$ higher in GCV-treated CD11b-TK ${ }^{\mathrm{mt}-30}$ mice compared with control groups at $7 \mathrm{~d}$ after lesion (Fig. 6a). This was further supported by the finding that the number of $\mathrm{CD} 68^{+}$macrophages that had ingested myelin debris, as visualized using ORO staining, was decreased by $\sim 66 \%$ in degenerating sciatic nerves of GCV-treated CD11b-TK ${ }^{\mathrm{mt}-30}$ mice compared with control groups at $7 \mathrm{~d}$ (data not shown). Examination of our sciatic nerve preparations also revealed that, although myelin debris clearance was severely compromised in the sciatic nerve distal stump of GCV-treated CD11b-TK ${ }^{\mathrm{mt}-30}$ transgenic mice (Fig. 6b,c), myelin breakdown and formation of ovoids of degenerating myelin was not prevented in these mice. Furthermore, we found that most of the remaining $\mathrm{CD}^{+} 8^{+}$macrophages (i.e., those not depleted by the GCV treatment) were filled with myelin debris. In our opinion, this may explain why macrophage depletion strategies did not completely abolish myelin debris clearance in this and another study (Brück et al., 1996). Still, we cannot rule out the possibility that Schwann cells may have also been involved in the phagocytosis of myelin debris, as suggested by others (Stoll et al., 1989; Reichert et al., 1994; Fernandez-Valle et al., 1995; Saada et al., 1996; Hirata and Kawabuchi, 2002).

Because some of the above-mentioned studies have suggested that myelin phagocytosis by Schwann cells may occur via a lectinmediated mechanism implicating Galectin-3, also referred to as Mac-2, we next investigated whether depletion of CD11b ${ }^{+}$myeloid cells may affect the expression of Galectin-3 in Schwann cells. Using immunohistochemistry, we first found that, although 

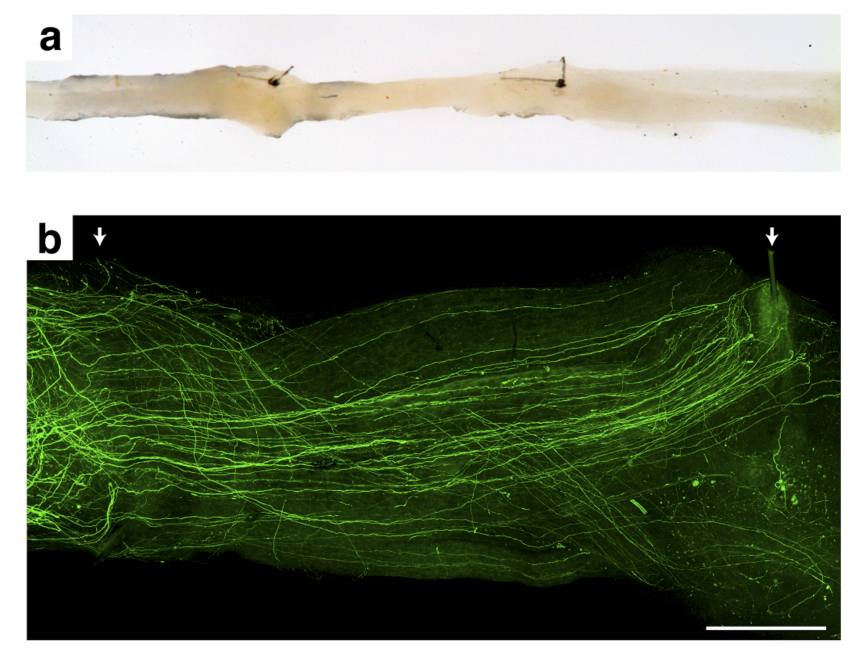

C

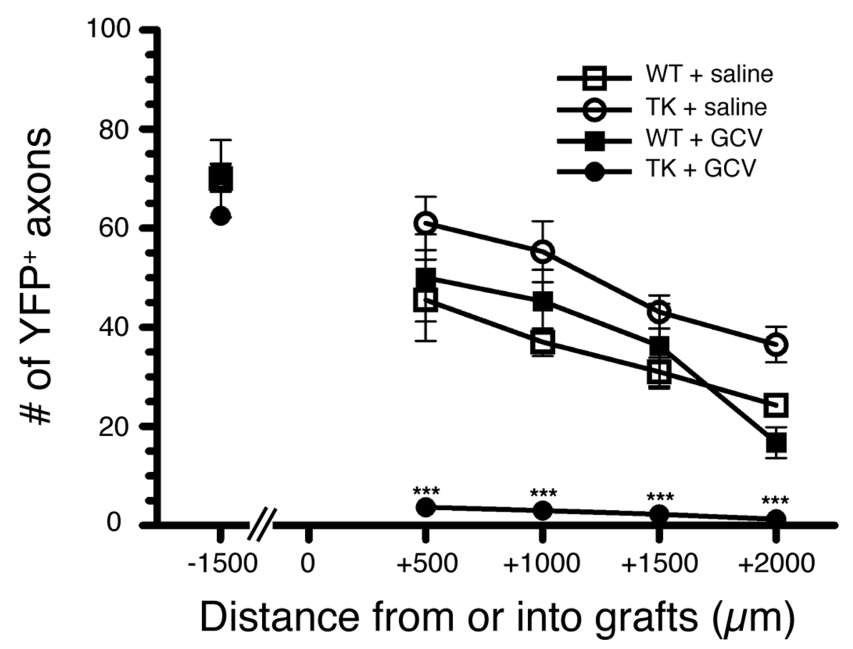

Figure 4. Regeneration of peripheral axons is prevented in the absence of CD11b ${ }^{+}$cells. $\boldsymbol{a}$, Photograph showing an example of sciatic-sciatic nerve graft. $\boldsymbol{b}$, Representative fluorescence photomicrograph showing sciatic nerve axons expressing the YFP marker that have regenerated into a PN graft collected from a saline-treated YFP ${ }^{-} / \mathrm{TK}^{+}$mouse (i.e., CD11b-TK ${ }^{\mathrm{mt}-30+/-}$ ). The arrows point to the two 10-0 sutures used to connect the $P N$ graft between the proximal and distal ends of the recipient sciatic nerve from the YFP transgenic mouse. c, Quantification of the number of YFP-labeled axons at predetermined distances from the proximal host-graft interface ( $n=8$ per group). Although the total number of YFP ${ }^{+}$axons was similar in all groups at a distance of $1.5 \mathrm{~mm}$ from the proximal host-graft interface (i.e., into the proximal end of the recipient sciatic nerve), YFP ${ }^{+}$axons were only able to regenerate into predegenerated PN grafts in the presence of $\mathrm{CD} 11 \mathrm{~b}{ }^{+}$cells. Error bars indicate SEM. ${ }^{* *} p<0.001$. Scale bar, $500 \mu \mathrm{m}$.

Galectin-3 signal was decreased in the sciatic nerve distal stump of GCV-treated CD11b-TK ${ }^{\mathrm{mt}-30}$ mice compared with control groups, protein levels remained relatively high in transgenic mice even in the absence of close to $90 \%$ of all CD $68^{+}$macrophages (supplemental Fig. $3 a-d$, available at www.jneurosci.org as supplemental material). These results therefore support the idea that Schwann cells are an important source of Galectin-3 after peripheral nerve injury. We then aimed to determine whether Schwann cell function related to myelin debris clearance could have been altered in the absence CD $11 b^{+}$myeloid cells. For this, flow cytometry was used to examine the expression of Galectin-3 in Schwann cells purified from sciatic nerve distal stump biopsies collected from mice generated from crossing S100 $\beta$-EGFP with CD11b-TK ${ }^{\mathrm{mt}-30}$ transgenic mice. In GCV-treated S100 $\beta$-EGFP/
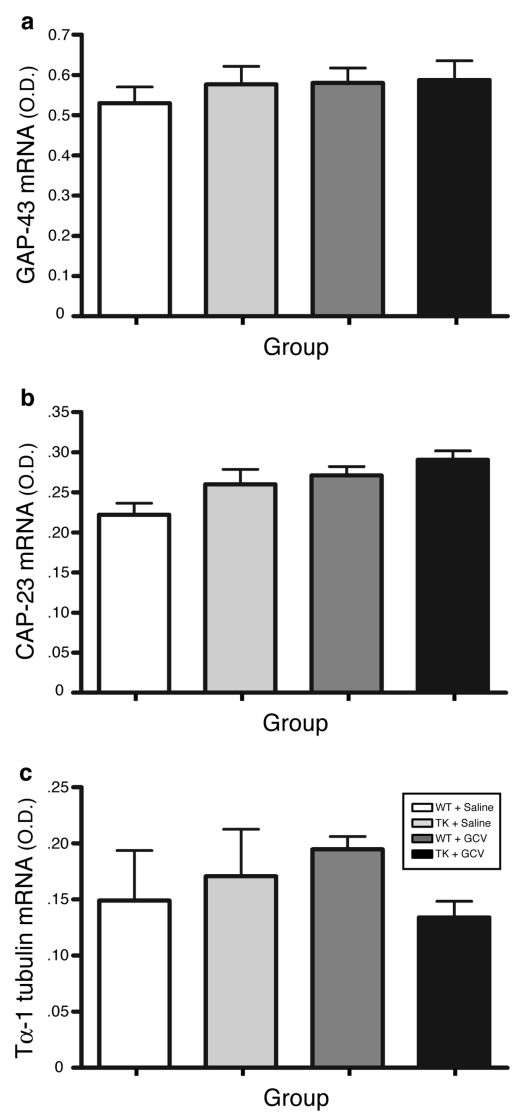

Figure 5. Cell bodies from axotomized sciatic motor neurons reacted normally to injury in the absence of $\mathrm{CD} 11 \mathrm{~b}^{+}$cells by overexpressing regeneration-associated genes. $\boldsymbol{a}-\boldsymbol{c}$, Quantification of in situ hybridization signal for GAP-43 (a), CAP-23 (b), and T $\alpha$-1 tubulin (c) mRNAs [in optical density (0.D.); arbitrary units] in the ipsilateral motoneuronal cell group of Rexed's lamina IX at spinal levels L2-L5 in CD11b-TK ${ }^{\mathrm{mt}-30+/-}$ (TK) and WT mice treated with either $\mathrm{GCV}$ or saline at $7 \mathrm{~d}$ after sciatic nerve lesion ( $n=8$ per group). Error bars indicate SEM.

CD11b-TK ${ }^{\mathrm{mt}-30}$ mice, we found that the proportion of Schwann cells expressing Galectin-3 was $68.9 \pm 8.6 \%$ at $7 \mathrm{~d}$ after lesion (supplemental Fig. $3 e$, available at www.jneurosci.org as supplemental material). This proportion did not differ significantly between groups, with percentages of $\mathrm{S} 100 \beta^{+} \mathrm{P} 75^{\mathrm{NTR}+}$ Galectin- ${ }^{+}$ of $79.3 \pm 4.8,76.9 \pm 5.7$, and $79.6 \pm 5.9 \%$ in saline-treated $\mathrm{WT}$, saline-treated $\mathrm{S} 100 \beta$-EGFP/CD11b-TK ${ }^{\mathrm{mt}-30}$, and GCV-treated WT mice, respectively. In summary, these results indicate that a major subset of Schwann cells express Galectin-3 at $7 \mathrm{~d}$ after peripheral nerve injury and that upregulation of the galactosespecific lectin does not depend on the presence CD11b ${ }^{+}$myeloid cells. Along these lines, the Rotshenker Laboratory (Saada et al., 1996) previously proposed that fibroblasts are responsible, through the production and release of granulocyte-macrophage colony-stimulating factor, for the upregulation of Galectin-3 in Schwann cells and macrophages in lesioned peripheral nerves.

Neurotrophin synthesis is prevented in the absence of CD11b ${ }^{+}$myeloid cells

Another way by which axon regeneration is regulated in the injured nervous system is through the release of growth factors such as neurotrophins by non-neuronal cells. One current dogma in the regeneration field is that Schwann cells in the peripheral nerve distal stump secrete neurotrophins in a macrophage-dependent manner (Heumann et al., 1987b; Lindholm et al., 1987). Thus, we next investigated whether neurotrophin synthesis would be com- 
promised after sciatic nerve lesion in the absence of CD $11 b^{+}$myeloid cells. Because neurotrophins are apparently expressed in low abundance and because specific antibodies for these growth factors that work well in fixed tissue sections are difficult to find, we chose to use radioactive ISH and highly specific RNA riboprobes to detect mRNAs coding for each of the four mammalian neurotrophins. This method has been used with great success by our laboratories in previous studies in which we reported the expression of cytokines/ growth factors in models of CNS diseases and injuries (Gowing et al., 2006b; Boivin et al., 2007). The specificity of our riboprobes was first tested in the adult mouse brain. As demonstrated in supplemental Figure 4 (available at www.jneurosci.org as supplemental material), the distribution of NGF, BDNF, NT-3, and NT-4/5 mRNAs using our radiolabeled cRNA probes and ISH protocol is similar to what has been reported by others in intact adult rat and mouse brains (Bandtlow et al., 1990; Hofer et al., 1990; Maisonpierre et al., 1990; Guthrie and Gall, 1991). Consistent with findings from these previous studies, both similarities and differences were observed in the distribution pattern of neurotrophin gene expression in the adult rodent brain.

Using ISH, we first performed a time course study to examine neurotrophin expression after sciatic nerve injury. For this, C57BL/6J mice were killed at $6 \mathrm{~h}$ and at 1 , $3,5,7,10$, and $14 \mathrm{~d}$ after lesion. In general, all neurotrophins had a similar pattern of expression. As expected, we found no hybridization signal for any of the neurotrophins analyzed on sciatic nerve sections obtained from noninjured mice. At $6 \mathrm{~h}$ after lesion, cells expressing neurotrophins were rare and strictly found at the lesion site, in close association with the epineurium. At $1 \mathrm{~d}$, more positive cells were seen, again closely associated with the epineurium and blood vessels irrigating the nerve. At $3 \mathrm{~d}$, neurotrophin-positive cells had already invaded the entire sciatic nerve distal stump, with cell numbers increasing over time up to day 14 after lesion, the latest time point analyzed. An example of NT-3 mRNA signal in the sciatic nerve distal stump at $7 \mathrm{~d}$ is shown in Figure $7 b$. Quantitative analyses of the number of cells expressing neurotrophins in the nerve distal stump showed that the number of NT-3 ${ }^{+}$(Fig. $\left.7 a\right), \mathrm{BDNF}^{+}$(supplemental Fig. $5 a-c$, available at www.jneurosci.org as supplemental material), $\mathrm{NGF}^{+}$(supplemental Fig. $5 d-f$, available at www.jneurosci.org as supplemental material), and NT-4/5 ${ }^{+}$(supplemental Fig. $5 g-i$, available at www.jneurosci.org as supplemental material) cells had decreased by $92,88,87$, and $86 \%$, respectively, in GCV-
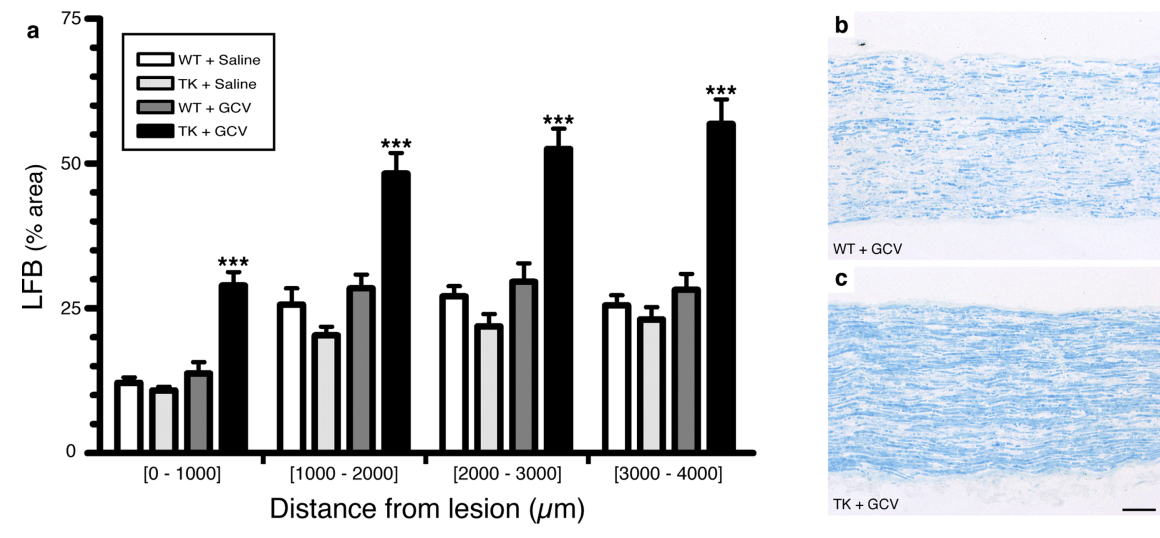

Figure 6. Inhibitory myelin debris could not be cleared in the absence of CD11b ${ }^{+}$cells. $a$, Quantification of LFB staining of myelin in the sciatic nerve distal stump of CD11b-TK ${ }^{\text {mt-30+/- }}$ (TK) and WT mice treated with either GCV or saline at $7 \mathrm{~d}$ after sciatic nerve lesion ( $n=8$ per group). Although myelin breakdown and formation of ovoids of degenerating myelin were apparent in the sciatic nerve distal stump of GCV-treated TK mice, quantification of LFB staining revealed that the load of myelin debris was $>200 \%$ higher in mice depleted in CD11b ${ }^{+}$cells compared with mice of control groups at $7 \mathrm{~d}$ after lesion. Error bars indicate SEM. $\boldsymbol{b}, \boldsymbol{c}$, Representative bright-field photomicrographs showing myelin stained with LFB in the sciatic nerve distal stump of GCVtreated WT and GCV-treated TK mice at $7 \mathrm{~d}$ after lesion. ${ }^{* *} p<0.001$. Scale bar: (in $\left.\boldsymbol{b}\right) \boldsymbol{b}, \boldsymbol{c}, 100 \mu \mathrm{m}$.
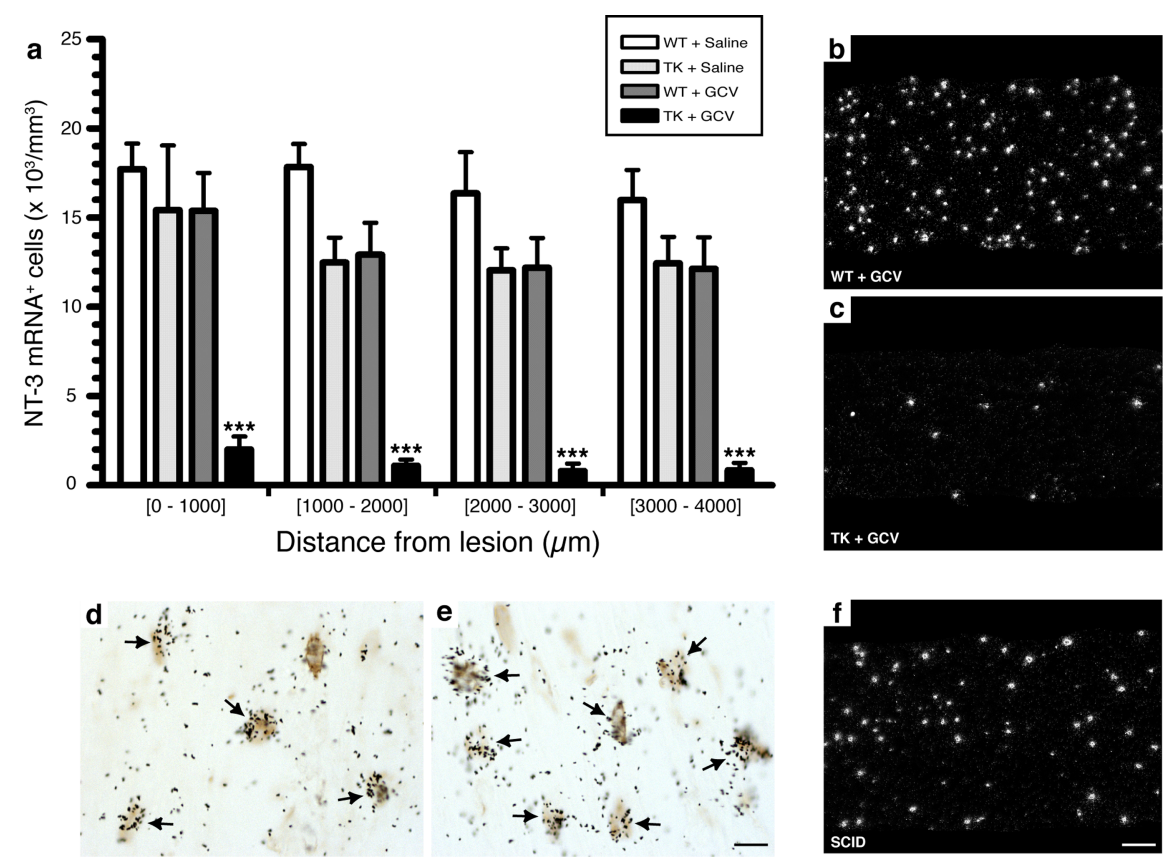

Figure 7. NT-3 synthesis in the injured peripheral nerve is prevented in the absence of CD11b ${ }^{+}$cells. $\boldsymbol{a}$, Quantification of the number of cells expressing NT-3 mRNA in the sciatic nerve distal stump of CD11b-TK ${ }^{\mathrm{mt}-30}$ (TK) and WT mice at $7 \mathrm{~d}$ after lesion in response to either $\mathrm{GCV}$ or saline treatment ( $n=8$ per group). Error bars indicate SEM. $\boldsymbol{b}, \boldsymbol{c}$, Representative dark-field photomicrographs showing NT-3 mRNA expression in the sciatic nerve distal stump of GCV-treated WT (b) and GCV-treated TK (c) mice at $7 \mathrm{~d}$ after lesion. $\boldsymbol{d}, \boldsymbol{e}$, Photomicrographs of the sciatic nerve distal stump of a WT mouse showing colocalization of NT-3 mRNA with Gr-1-immunoreactive granulocytes/inflammatory monocytes. The arrows point to double-labeled cells. $f$, Representative darkfield photomicrograph showing the presence of numerous cells expressing NT-3 mRNA in the sciatic nerve distal stump of a scid mouse that has no functional T- and B-cells at $7 \mathrm{~d}$ after lesion. Together, these results indicate that a subset of CD11b ${ }^{+}$myeloid cells expressing the cell surface protein $\mathrm{Gr}-1$ are responsible for neurotrophin synthesis in the injured peripheral nerve. ${ }^{* * *} p<$ 0.001. Scale bars: (in $\boldsymbol{e}) \boldsymbol{d}, \boldsymbol{e}, 5 \mu \mathrm{m}$; (in $\boldsymbol{f}) \boldsymbol{b}, \boldsymbol{c}, \boldsymbol{f}, 100 \mu \mathrm{m}$. 
(Lindholm et al., 1987), double-labeling studies combining ISH with immunohistochemistry were performed on the same sciatic nerve section. Results showed that granulocytes and/or a subset of monocytes expressing Gr- $1^{+}$were the main, if not only, cellular source of neurotrophins in the injured sciatic nerve (Fig. $7 d, e$ ). Not surprisingly, scid mice (NOD/CB17-Prkdc ${ }^{\text {scid } / J ~ m i c e) ~ t h a t ~}$ have no functional $\mathrm{T}$ - and $\mathrm{B}$-cells were still capable of expressing neurotrophins after sciatic nerve injury (Fig. $7 f$ ). These results are well in line with our previous finding that GCV treatment in $\mathrm{CD} 11 \mathrm{~b}-\mathrm{TK}^{\mathrm{mt}-30}$ transgenic mice had very limited effects on $\mathrm{T}$ and B-cell recruitment after peripheral nerve injury, although neurotrophin synthesis was almost completely prevented in these mice. Together, these results demonstrate that, in vivo, Gr-1 ${ }^{+}$ granulocytes/inflammatory monocytes are recruited to the injured peripheral nervous system and may contribute to nerve regeneration and repair through the production of neurotrophins.

\section{The formation/stabilization of blood vessels is compromised in the absence of $\mathrm{CD}_{11 \mathrm{~b}}{ }^{+}$myeloid cells}

During the course of this study, we also observed that a certain percentage of axons that regenerate into $\mathrm{PN}$ grafts grew along the trajectory of blood vessels (Fig. $8 a-g$ ). We therefore asked whether depletion in $\mathrm{CD} 11 \mathrm{~b}^{+}$cells could have affected the formation/stabilization of blood vessels in the injured peripheral nerve, because angiogenesis and axonal regeneration may be regulated by common cues/factors. To test this, we performed immunohistochemistry against the endothelial marker CD31 and found that the number of blood vessels was significantly decreased in the sciatic nerve distal stump of GCV-treated CD11b$\mathrm{TK}^{\mathrm{mt}-30}$ mice compared with all other groups (Fig. 8h-j,o-r). These results were confirmed by another method of quantification in which the proportional area of tissue occupied by CD31 immunofluorescence was measured. Using this type of analysis, results showed that the area occupied by blood vessels in the sciatic nerve distal stump was reduced by $\sim 75 \%$ in mice depleted in $\mathrm{CD}_{11 \mathrm{~b}}{ }^{+}$cells compared with control groups (data not shown). Importantly, the number of $\mathrm{CD} 31^{+}$blood vessels in the contralateral nerve (unlesioned) was equivalent for all groups (Fig. $8 k-n$ ), indicating that ganciclovir treatment did not cause vessel death. Finally, we found that cells expressing the Tie 2 angiopoietin receptor, which were recognized for their proangiogenic properties and may account for $1-15 \%$ of all CD $11 b^{+}$myeloid cells (De Palma et al., 2003, 2005), were absent from the injured sciatic nerve of GCV-treated CD11b-TK ${ }^{\mathrm{mt}-30}$ transgenic mice (Fig. $8 s, t$ ). These results indicate that myeloid cells, or a subset of these cells expressing CD11b, are essential for the formation/stabilization of blood vessels in the injured nervous system. We suggest that specific factors produced by these CD $11 \mathrm{~b}^{+}$ myeloid cells regulate axonal growth and blood vessel formation/stabilization.

\section{Regeneration of spinal cord-injured axons into PN grafts is compromised in mice depleted in $\mathrm{CD}_{11} \mathrm{~b}^{+}$cells}

The preceding experiments demonstrated that $\mathrm{CD} 11 \mathrm{~b}^{+}$cells regulate peripheral axon regeneration after injury by creating a growth-permissive environment at the growth cone level. More specifically, they showed that $\mathrm{CD} 11 \mathrm{~b}^{+}$cells are responsible for clearance of inhibitory myelin debris, neurotrophin synthesis, and blood vessel formation/stabilization in the nerve distal stump. However, whether regeneration of lesioned CNS axons into PN grafts depends on the presence of CD11b ${ }^{+}$myeloid cells remains unknown. To study this, predegenerated peripheral nerve grafts depleted or not in $\mathrm{CD} 11 \mathrm{~b}^{+}$cells were implanted into the injured spinal cord of $\mathrm{YFP}^{+}$recipient mice at the thoracolumbar junction (Fig. 9a). Examples of YFP fluorescence observed within the thoracic and lumbar spinal cord of a thy1YFP-H recipient mouse are shown in Figure 9, $b$ and $c$. Note that axons from almost all spinal axon tracts express YFP in these mice. PN grafts were first identified in histological sections using laminin immunolabeling and the number of SCI YFP fluorescent axons that had regenerated into grafts counted (Fig. $9 d, e$ ). As for peripheral axons, central axons almost completely failed to regenerate into PN grafts in the absence of CD11b ${ }^{+}$cells (Fig. $9 f$ ). On average, we counted $<1 \mathrm{YFP}^{+}$axons per graft (i.e., $0.8 \pm 0.5$ axon per graft) in nerve grafts obtained from GCV-treated CD11b-TK ${ }^{\mathrm{mt}-30}$ mice at 1 week after grafting/treatment. This represents a decrease of at least $85 \%$ compared with average axonal numbers counted in other groups. Together with our previous finding that regeneration of sciatic nerve axons is abolished in GCV-treated CD11b-TK ${ }^{\mathrm{mt}-30}$ mice, these results indicate that myeloid cells are required for both peripheral and central axon regeneration.

\section{Discussion}

Here, we investigated the long-term effects of persistent granulocyte and macrophage depletion after neural injury. Longitudinal macrophage depletion studies have not been possible in the past because of their reported toxicity for animals. Here, we bypassed this problem by using transgenic mice expressing a suicide gene under the control of the myeloid-specific CD11b gene promoter and a new drug delivery approach to continuously and directly infuse the prodrug GCV at the site of sciatic nerve lesion for prolonged periods of times. Using this model, we were able to deplete the number of $\mathrm{Gr}-1^{+}$granulocytes/inflammatory monocytes and $\mathrm{CD}_{68}{ }^{+}$macrophages by 98 and $89 \%$, respectively, in the injured peripheral nerve of transgenic mice. Depletion of $\mathrm{CD}_{11} \mathrm{~b}^{+}$cells had limited effects on the infiltration of T- and B-cells and did not affect Schwann cell number in the sciatic nerve distal stump. Thus, the use of the CD11b-TK ${ }^{\mathrm{mt}-30}$ transgenic mice in the present study represented a model of choice to clarify the role of CD11 ${ }^{+}$cells after neural injury.

Surprisingly little is known regarding the exact consequences of depleting specific subsets of myeloid cells after neural injury. Whether peripheral nerve regeneration depends on the presence of supporting cells within and beyond the site of injury had been controversial for many years until studies demonstrated that the success of axonal regeneration through acellular nerve grafts depended on the migration of cells into the grafts (for review, see Fu and Gordon, 1997). In these studies, however, the populations of cells responsible for these effects were never clearly identified, and to this day, many assumed that Schwann cells were solely responsible for the regeneration of peripheral axons. Here, we show that recovery of sciatic nerve functions was severely compromised in mice depleted in $\mathrm{CD}_{11 \mathrm{~b}^{+}}$cells, with large deficits persisting for as long as myeloid cells were depleted. Importantly, no difference was observed in the number of Schwann cells detected in the sciatic nerve distal stump of transgenic and control mice. This result is consistent with reports from two other groups who recently demonstrated that a partial depletion in macrophages has very limited effects on Schwann cell proliferation after sciatic nerve injury (Kubota and Suzuki, 2000; Gray et al., 2007). Although it is possible that depletion of $\mathrm{CD} 11 \mathrm{~b}^{+}$cells may have altered Schwann cell gene expression without influencing their proliferation, these results demonstrate the importance of myeloid cells for nerve repair and recovery of neurological functions. 


\section{a}

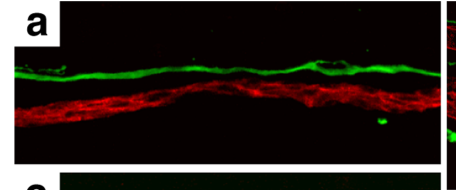

c

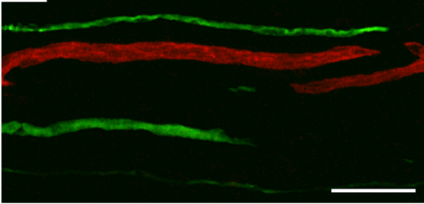

e

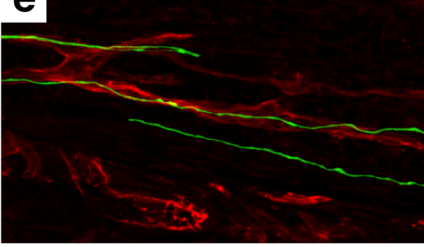

f

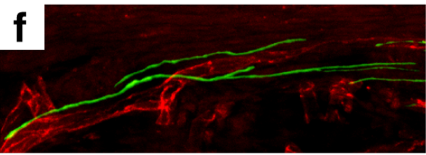

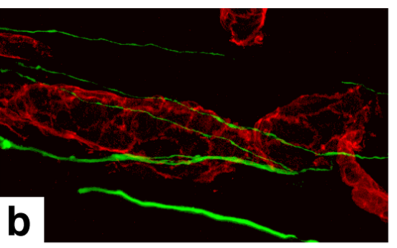

b

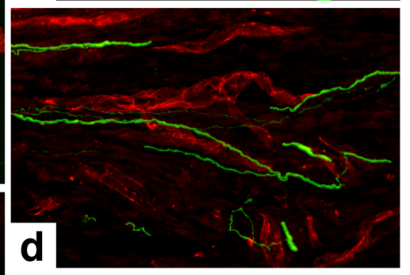

$\mathbf{g}$
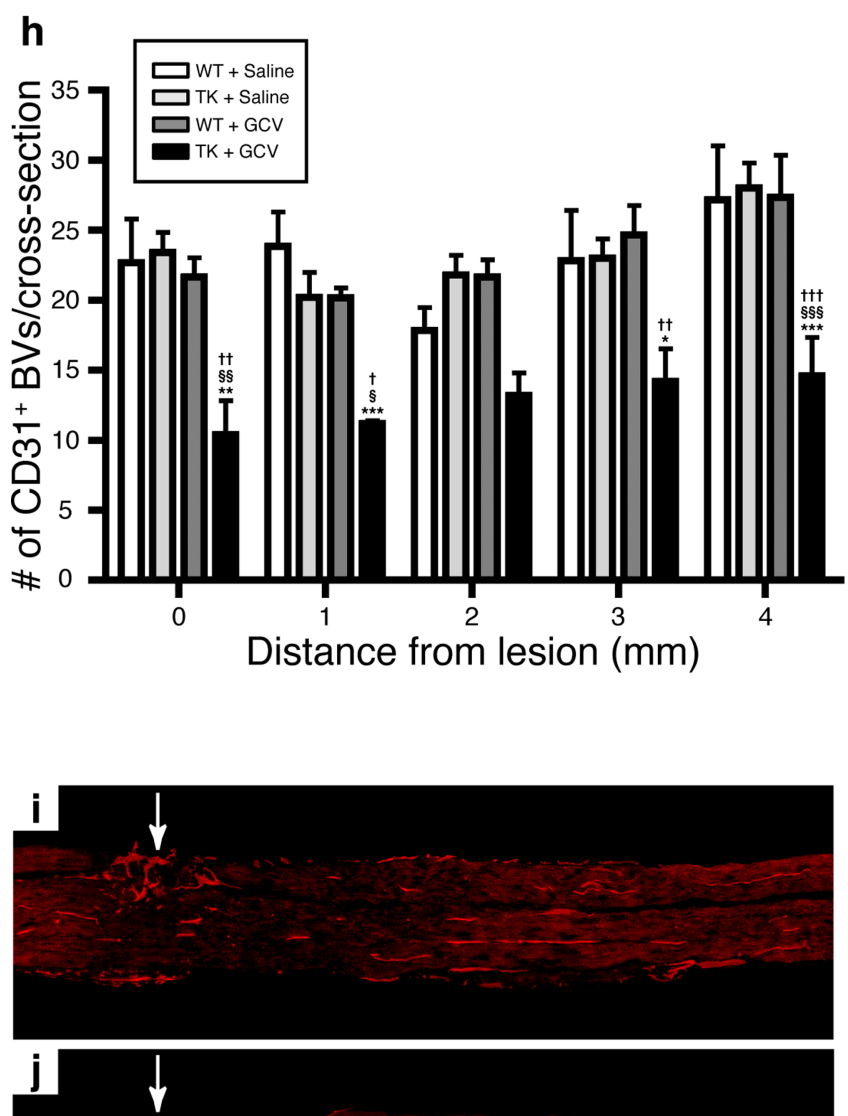
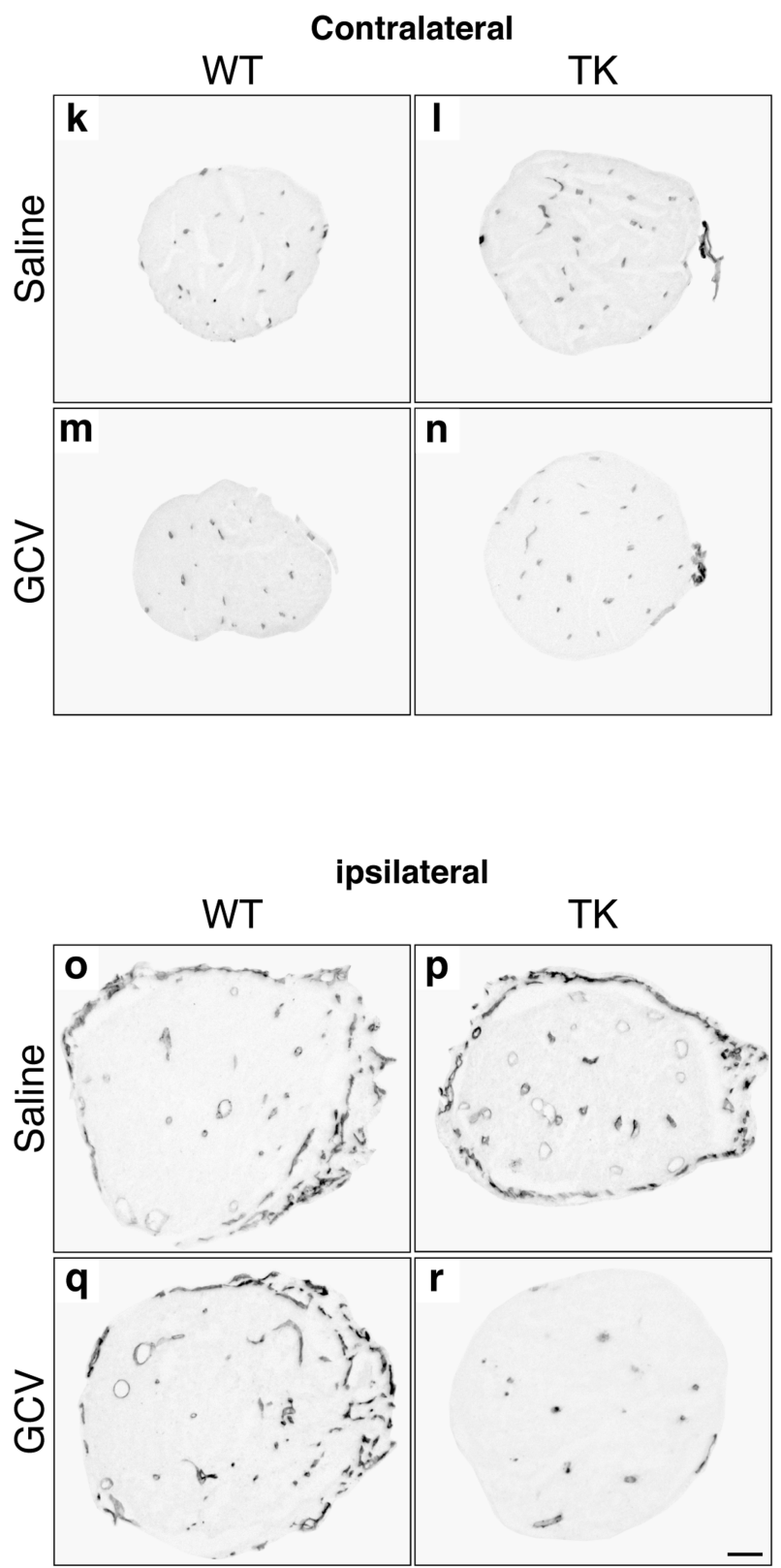

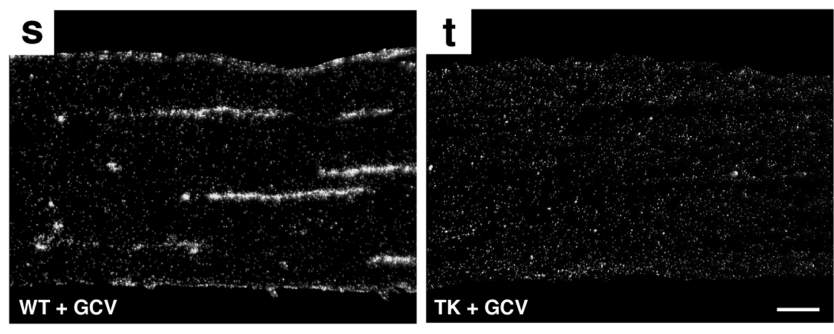

Figure 8. The formation/stabilization of blood vessels in the injured peripheral nerve is compromised after depletion of CD11b ${ }^{+}$cells. $\boldsymbol{a}-\boldsymbol{g}$, Fluorescence photomicrographs showing examples of sciatic nerve- $(\boldsymbol{a}-\boldsymbol{c})$ and spinal cord-injured $(\boldsymbol{d}-\boldsymbol{g})$ axons (green) regenerating into peripheral nerve grafts in close association with blood vessels (CD31 immunolabeling; red). $\boldsymbol{h}$, Quantification of the number of CD31-immunoreactive blood vessels at predetermined distances from the lesion site in the sciatic nerve distal stump of CD11b-TK ${ }^{\mathrm{mt}-30}$ (TK) (Figure legend continues.) 
Using in vivo models of peripheral nerve grafts, we established that $\mathrm{CD} 11 \mathrm{~b}^{+}$myeloid cells are required for regeneration of peripheral nerve axons and that the presence of these cells can even support regeneration of SCI axons. Finally, we defined some of the key mechanisms by which $\mathrm{CD} 11 \mathrm{~b}^{+}$cells support axonal regeneration and neural repair. Specifically, we found that $\mathrm{CD}_{11 \mathrm{~b}}{ }^{+}$cells are responsible for the removal of inhibitory myelin debris, production of neurotrophins, and formation and stabilization of blood vessels in the injured nervous system.

One likely mechanism by which $\mathrm{CD} 11 \mathrm{~b}^{+}$myeloid cells may contribute to a permissive environment for axon growth is through the clearance of degenerating myelin and inhibitors of axonal regeneration. Several proteins associated with myelin have been shown to inhibit neurite outgrowth or collapse growth cones, including Nogo-A, MAG, OMgp (oligodendrocyte myelin glycoprotein), ephrin B3, and semaphorin 4D (David and Lacroix, 2003; Yiu and He, 2006). Although some of these proteins are not expressed in the injured PNS, MAG and semaphorins are and could contribute to prevent axon regeneration (Liu et al., 2006). After peripheral nerve injury, immune cells such as $\mathrm{CD}_{11 \mathrm{~b}}{ }^{+}$macrophages are rapidly recruited and eliminate myelin debris within 10-14 d (George and Griffin, 1994). This observation is consistent with our results showing that the load of myelin debris was $>200 \%$ higher in animals depleted in CD $11 \mathrm{~b}^{+}$ cells compared with wild-type littermates at $7 \mathrm{~d}$ after injury. This suggests that myelin debris were not removed efficiently in the absence of $\mathrm{CD} 11 \mathrm{~b}^{+}$cells. It should be pointed out, however, that myelin breakdown and the formation of ovoids of degenerating myelin were apparent in the distal sciatic nerve segment of GCVtreated $\mathrm{CD} 11 \mathrm{~b}-\mathrm{TK}^{\mathrm{mt}-30}$ transgenic mice, indicating that these responses did not depend on $\mathrm{CD}_{11} \mathrm{~b}^{+}$cells. Overall, these findings suggest that $\mathrm{CD} 1 \mathrm{bb}^{+}$macrophages are primarily, although perhaps not entirely, responsible for the phagocytosis and removal of myelin debris and its inhibitory effects.

Peripheral nerve injury leads to the expression of a wide variety of neurotrophic factors, notably neurotrophins (Fu and Gordon, 1997; Terenghi, 1999). Neurotrophins, which include NGF, BDNF, NT-3, and NT-4/5, are well known for their capacity to promote neuronal survival and axon growth in the PNS and CNS (Lacroix and Tuszynski, 2000). Addition of exogenous neurotrophins to the injured peripheral nerve environment has been reported to facilitate axon regeneration and remyelination and to improve functional recovery, whereas blocking these factors was found to compromise regeneration and cause additional deficits in recovery of nerve functions (Terenghi, 1999; Lykissas et al., 2007). Despite abundant evidence showing that neurotrophins are key molecules for nerve regeneration and repair, the cellular and molecular mechanisms regulating neurotrophin synthesis

(Figure legend continued.) and WT mice at $7 \mathrm{~d}$ after lesion in response to either GCV or saline treatment ( $n=8$ per group). Error bars indicate SEM. $\boldsymbol{i}, \boldsymbol{j}$, Representative photomicrographs showing immunofluorescence for $C D 31$ in the sciatic nerve distal stump of WT $(i)$ and TK $(j)$ mice treated with $\mathrm{GCV}$ at $7 \mathrm{~d}$ after lesion. The arrows point to the lesion site. $\boldsymbol{k}-\boldsymbol{r}$, Representative bright-field photomicrographs showing immunoreactivity for CD31 in sciatic nerve cross sections taken from contralateral (unlesioned) and ipsilateral (lesioned) nerves of WT and TK mice treated with either saline or GCV at $7 \mathrm{~d}$ after lesion. $\boldsymbol{s}, \boldsymbol{t}$, Representative dark-field photomicrographs showing Tie2 mRNA expression in the sciatic nerve distal stump of GCV-treated WT and GCV-treated TK mice at $7 \mathrm{~d}$ after lesion. Note the absence of Tie2 mRNA signal after depletion of $\mathrm{CD}_{11 \mathrm{~b}}{ }^{+}$cells. ${ }^{* * *} p<0.001,{ }^{* *} p<0.01$, and ${ }^{*} p<0.05$ compared with the WT plus saline group; ${ }^{{ } \S} p<0.001,{ }^{\$ \S} p<0.01$, and ${ }^{\$} p<0.05$ compared with the TK plus saline group; ${ }^{+{ }^{+\dagger}} p<0.001,{ }^{+\dagger} p<0.01$, and ${ }^{\dagger} p<0.05$ compared with the WT plus GCV group. Scale bars: (in c) $\boldsymbol{a}-\boldsymbol{c}, 50 \mu \mathrm{m}$; (in $\boldsymbol{g}$ ) $\boldsymbol{d}-\boldsymbol{g}, 50 \mu \mathrm{m}$; (in j) $\boldsymbol{i}, \boldsymbol{j}, 250 \mu \mathrm{m}$; (in $\boldsymbol{r}$ ) $\boldsymbol{k}-\boldsymbol{r}, 80 \mu \mathrm{m}$; (in $\boldsymbol{t}) \boldsymbol{s}, \boldsymbol{t}, 100 \mu \mathrm{m}$.
}

have yet to be fully investigated. The Thoenen Laboratory reported the first evidence that immune cells might play a role in regulating neurotrophin synthesis after neural injury. They observed that NGF mRNA levels decrease over time when sciatic nerve is kept in culture, and that NGF levels increase when activated macrophages are added to the culture medium (Heumann et al., 1987b). In a subsequent study, they found that IL- $1 \beta$ derived from macrophages was responsible for the synthesis of NGF by non-neuronal cells after sciatic nerve injury (Lindholm et al., 1987). Based on the time course of BDNF expression, they further suggested that different regulatory mechanisms were likely to control NGF and BDNF expression in the injured peripheral nerve in vivo. To clarify this issue and investigate the possibility that $\mathrm{CD} 11 \mathrm{~b}^{+}$myeloid cells may also contribute to nerve regeneration through the production of neurotrophic factors, we examined whether depletion of $\mathrm{CD}_{1} \mathrm{~b}^{+}$would affect neurotrophin synthesis after sciatic nerve injury.

In line with previous studies (Heumann et al., 1987a,b; Funakoshi et al., 1993), our results show that NGF, BDNF, and NT-4/5 expression was absent in the intact sciatic nerve but induced in non-neuronal cells of the nerve distal stump after injury. Our results differ, however, from the study by Funakoshi et al. (1993) with regard to the expression of NT-3, which we found to be regulated exactly like the other three neurotrophins. The differences observed between the study by Funakoshi et al. (1993) and ours are discussed in more details the supplemental Discussion (available at www.jneurosci.org as supplemental material). Additional analyses using CD11b-TK ${ }^{\mathrm{mt}-30}$ transgenic mice revealed that neurotrophin expression was almost completely abolished in animals depleted in CD11b ${ }^{+}$cells. Double-labeling studies combining ISH with immunohistochemistry and experiments performed in scid mice that have no functional T- and B-cells confirmed that granulocytes and/or a subset of monocytes expressing the Gr-1 marker were the main, if not only, cellular source of neurotrophins in the injured sciatic nerve at 1 week after lesion. Work is currently underway to determine the exact phenotype of these cells.

Another particularly intriguing observation that we made during the course of this study is that the formation of new blood vessels at the lesion site and within the nerve distal stump was almost completely prevented in mice depleted in $\mathrm{CD}_{11 \mathrm{~b}^{+}}$cells. This, together with the fact that we found no evidence of GFP ${ }^{+}$ endothelial cells in blood vessels of GFP bone marrow chimeric mice after peripheral nerve injury (S. Lacroix, unpublished observations), suggests that $\mathrm{CD} 11 \mathrm{~b}^{+}$cells are essential for vessel formation after nerve injury but unlikely to develop into endothelial-like cells, as suggested by others when cultured under certain experimental conditions (for review, see De Palma and Naldini, 2006). Interestingly, Gray et al. (2007) reported in their recent macrophage depletion study the presence of significantly less Evans blue albumin (used as a marker of blood vessel integrity) in their sciatic nerve preparations after injury. Although this issue was not investigated in their study, one possible interpretation of these results is that de novo vessel formation was compromised in sciatic nerves of these animals in the absence of monocytes/macrophages. A proangiogenic role for a specific subtype of myeloid cells expressing the Tie 2 angiopoietin receptor and representing $\sim 1-15 \%$ of all $\mathrm{CD}_{11 \mathrm{~b}}{ }^{+}$myeloid cells has been reported before in a brain tumor model (De Palma et al., 2003, 2005). The demonstration that cells expressing Tie 2 were depleted in the sciatic nerve distal stump of GCV-treated CD11b$\mathrm{TK}^{\mathrm{mt}-30}$ transgenic mice supports the possibility that such a population of myeloid cells $\left(\mathrm{CD} 11 \mathrm{~b}^{+} \mathrm{Tie} 2^{+}\right)$may have been 
instrumental to the formation of new blood vessels. Some of the potential mechanisms by which $\mathrm{CD}_{11 \mathrm{~b}^{+}}$myeloid cells could regulate blood vessel formation/ stabilization are discussed in the supplemental Discussion (available at www. jneurosci.org as supplemental material).

Together, the results discussed above could help resolve a long-standing controversy regarding the potentially beneficial effects of transplanting macrophages into the injured spinal cord (Schwartz and Yoles, 2006; Donnelly and Popovich, 2008). This controversy stemmed mostly from two separate studies, one that reported that macrophages preincubated with sciatic nerve segments can promote partial recovery of motor functions once transplanted into the fully transected rat spinal cord (Rapalino et al., 1998) and another that showed that depletion of bloodderived macrophages decreases tissue damage and promotes recovery of hindlimb function after spinal cord contusion (Popovich et al., 1999). Perhaps monocytes/macrophages play a role in both tissue damage and repair, depending on the cellular population involved and their state of activation. Additional studies are therefore needed to investigate whether a specific subset of the macrophages that were transplanted or depleted into the injured spinal cord were responsible for the reported beneficial and detrimental effects, respectively. Along these lines, the existence of at least two monocyte subsets with divergent but complementary functions was recently demonstrated (Auffray et al., 2007; Nahrendorf et al., 2007). According to these studies, one of these two subsets, termed inflammatory monocytes $\left(\mathrm{Gr}-1^{\text {high }} / \mathrm{CCR} 2^{+} / \mathrm{CX}_{3} \mathrm{CR} 1^{\text {low }}\right)$, are recruited to injured tissues via the CCR2 receptor and are primarily involved in inflammation, proteolysis, and phagocytosis. The other monocytic population, termed Gr- ${ }^{\text {low }} / \mathrm{CCR} 2^{-}$/ $\mathrm{CX}_{3} \mathrm{CR} 1^{\text {high }}$ monocytes, respond to a different chemokine, fractalkine (also referred to as $\mathrm{CX}_{3} \mathrm{CL} 1$ ), and is apparently implicated in both immune surveillance and the healing process. A role for $\mathrm{Gr}-1^{\text {low }} /$

$\mathrm{CX}_{3} \mathrm{CR} 1^{\text {high }}$ monocytes in angiogenesis has also been suggested (Nahrendorf et al., 2007). Clearly, more studies are needed to better define the exact roles of the various monocyte/macrophage subsets after injury to the nervous system.

In conclusion, our results indicate that $\mathrm{CD} 11 \mathrm{~b}^{+}$myeloid cells modulate axonal regeneration after injury by directly influencing the growth cone dynamics through the creation of a more favorable growth environment. These cells contribute to recreate a permissive milieu for regeneration of injured peripheral and central axons through the removal of inhibitory myelin debris and release of neurotrophic and proangiogenic factors.
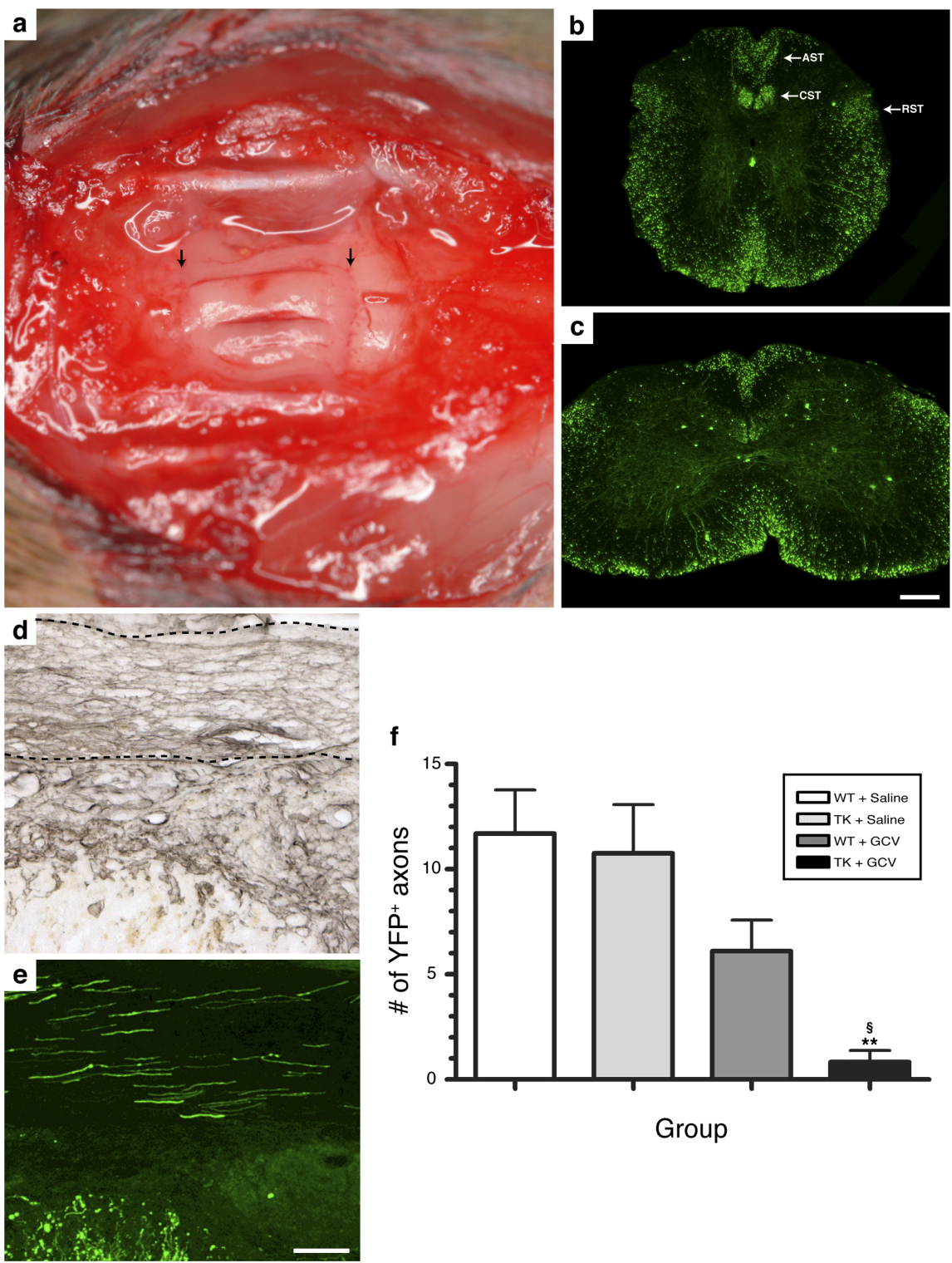

Group

Figure 9. Regeneration of $\mathrm{SCl}$ axons into PN grafts is prevented in the absence of $\mathrm{CD} 11 \mathrm{~b}{ }^{+}$cells. $\boldsymbol{a}$, Photograph showing three sciatic nerve segments transplanted into the spinal cord of a T12/L1 dorsal hemisected Thy1-YFP-H ${ }^{+/-}$transgenic mouse. The arrows point to PN grafts/spinal cord tissue interfaces. $\boldsymbol{b}, \boldsymbol{c}$, YFP expression in the thoracic $(\boldsymbol{b})$ and lumbar $(\boldsymbol{c})$ spinal cord of a Thy1-YFP-H ${ }^{+/-}$transgenic mouse. Note the presence of fluorescence in axons traveling through most, if not all, spinal cord projection systems, including the descending corticospinal (CST) and rubrospinal (RST) tracts and the ascending sensory tract (AST). $\boldsymbol{d}, \boldsymbol{e}$, Visualization of laminin immunolabeling ( $\boldsymbol{d}$ ) (to visualize PN tissue) and YFP fluorescence $(\boldsymbol{e})$ on adjacent spinal cord sections revealed that $\mathrm{PN}$ grafts are densely penetrated by regenerating $\mathrm{SCl}$ axons at 2 weeks after $\mathrm{SCl} / \mathrm{grafting}$. The dotted lines in $\boldsymbol{d}$ indicate the anatomical boundaries of a PN graft. $\boldsymbol{f}$, Quantification of the number of YFP-labeled axons at predetermined distances from the rostrocaudal host- graft interface. Note that SCI YFP-labeled axons did not regenerate into predegenerated PN grafts lacking CD11b ${ }^{+}$cells. Error bars indicate SEM. ${ }^{* *} p<0.01$ compared with the WT plus saline group; ${ }^{\S} p<0.05$ compared with the TK plus saline group. Scale bars: (in c) $b, c, 275 \mu \mathrm{m}$; (in $\boldsymbol{e}) \boldsymbol{d}, \boldsymbol{e}, 100 \mu \mathrm{m}$.

\section{References}

Auffray C, Fogg D, Garfa M, Elain G, Join-Lambert O, Kayal S, Sarnacki S, Cumano A, Lauvau G, Geissmann F (2007) Monitoring of blood vessels and tissues by a population of monocytes with patrolling behavior. Science 317:666-670.

Bandtlow CE, Meyer M, Lindholm D, Spranger M, Heumann R, Thoenen H (1990) Regional and cellular codistribution of interleukin 1 beta and nerve growth factor mRNA in the adult rat brain: possible relationship to the regulation of nerve growth factor synthesis. J Cell Biol 111:1701-1711.

Barrette B, Vallieres N, Dube M, Lacroix S (2007) Expression profile of receptors for myelin-associated inhibitors of axonal regeneration in the intact and injured mouse central nervous system. Mol Cell Neurosci 34:519-538. 
Boivin A, Pineau I, Barrette B, Filali M, Vallières N, Rivest S, Lacroix S (2007) Toll-like receptor signaling is critical for Wallerian degeneration and functional recovery after peripheral nerve injury. J Neurosci 27:12565-12576.

Brück W, Huitinga I, Dijkstra CD (1996) Liposome-mediated monocyte depletion during wallerian degeneration defines the role of hematogenous phagocytes in myelin removal. J Neurosci Res 46:477-484.

Carmeliet P, Tessier-Lavigne M (2005) Common mechanisms of nerve and blood vessel wiring. Nature 436:193-200.

Dahlin LB (1995) Prevention of macrophage invasion impairs regeneration in nerve grafts. Brain Res 679:274-280.

David S, Aguayo AJ (1981) Axonal elongation into peripheral nervous system "bridges" after central nervous system injury in adult rats. Science 214:931-933.

David S, Lacroix S (2003) Molecular approaches to spinal cord repair. Annu Rev Neurosci 26:411-440.

de Medinaceli L, Freed WJ, Wyatt RJ (1982) An index of the functional condition of rat sciatic nerve based on measurements made from walking tracks. Exp Neurol 77:634-643.

De Palma M, Naldini L (2006) Role of haematopoietic cells and endothelial progenitors in tumour angiogenesis. Biochim Biophys Acta 1766:159-166.

De Palma M, Venneri MA, Roca C, Naldini L (2003) Targeting exogenous genes to tumor angiogenesis by transplantation of genetically modified hematopoietic stem cells. Nat Med 9:789-795.

De Palma M, Venneri MA, Galli R, Sergi Sergi L, Politi LS, Sampaolesi M, Naldini L (2005) Tie2 identifies a hematopoietic lineage of proangiogenic monocytes required for tumor vessel formation and a mesenchymal population of pericyte progenitors. Cancer Cell 8:211-226.

Donnelly DJ, Popovich PG (2008) Inflammation and its role in neuroprotection, axonal regeneration and functional recovery after spinal cord injury. Exp Neurol 209:378-388.

English AW, Meador W, Carrasco DI (2005) Neurotrophin-4/5 is required for the early growth of regenerating axons in peripheral nerves. Eur J Neurosci 21:2624-2634.

Feng G, Mellor RH, Bernstein M, Keller-Peck C, Nguyen QT, Wallace M, Nerbonne JM, Lichtman JW, Sanes JR (2000) Imaging neuronal subsets in transgenic mice expressing multiple spectral variants of GFP. Neuron 28:41-51.

Fernandez-Valle C, Bunge RP, Bunge MB (1995) Schwann cells degrade myelin and proliferate in the absence of macrophages: evidence from in vitro studies of Wallerian degeneration. J Neurocytol 24:667-679.

Folkman J (2007) Angiogenesis: an organizing principle for drug discovery? Nat Rev Drug Discov 6:273-286.

Fu SY, Gordon T (1997) The cellular and molecular basis of peripheral nerve regeneration. Mol Neurobiol 14:67-116.

Funakoshi H, Frisén J, Barbany G, Timmusk T, Zachrisson O, Verge VM, Persson H (1993) Differential expression of mRNAs for neurotrophins and their receptors after axotomy of the sciatic nerve. J Cell Biol 123:455-465.

George R, Griffin JW (1994) Delayed macrophage responses and myelin clearance during Wallerian degeneration in the central nervous system: the dorsal radiculotomy model. Exp Neurol 129:225-236.

Gowing G, Vallières L, Julien JP (2006a) Mouse model for ablation of proliferating microglia in acute CNS injuries. Glia 53:331-337.

Gowing G, Dequen F, Soucy G, Julien JP (2006b) Absence of tumor necrosis factor- $\alpha$ does not affect motor neuron disease caused by superoxide dismutase 1 mutations. J Neurosci 26:11397-11402.

Gray M, Palispis W, Popovich PG, van Rooijen N, Gupta R (2007) Macrophage depletion alters the blood-nerve barrier without affecting Schwann cell function after neural injury. J Neurosci Res 85:766-777.

Guthrie KM, Gall CM (1991) Differential expression of mRNAs for the NGF family of neurotrophic factors in the adult rat central olfactory system. J Comp Neurol 313:95-102.

Hall SM (1986) The effect of inhibiting Schwann cell mitosis on the reinnervation of acellular autografts in the peripheral nervous system of the mouse. Neuropathol Appl Neurobiol 12:401-414.

Harel NY, Strittmatter SM (2006) Can regenerating axons recapitulate developmental guidance during recovery from spinal cord injury? Nat Rev Neurosci 7:603-616.

Heppner FL, Greter M, Marino D, Falsig J, Raivich G, Hövelmeyer N, Waisman A, Rülicke T, Prinz M, Priller J, Becher B, Aguzzi A (2005) Experi- mental autoimmune encephalomyelitis repressed by microglial paralysis. Nat Med 11:146-152.

Heumann R, Korsching S, Bandtlow C, Thoenen H (1987a) Changes of nerve growth factor synthesis in nonneuronal cells in response to sciatic nerve transection. J Cell Biol 104:1623-1631.

Heumann R, Lindholm D, Bandtlow C, Meyer M, Radeke MJ, Misko TP, Shooter E, Thoenen H (1987b) Differential regulation of mRNA encoding nerve growth factor and its receptor in rat sciatic nerve during development, degeneration, and regeneration: role of macrophages. Proc Natl Acad Sci U S A 84:8735-8739.

Hirata K, Kawabuchi M (2002) Myelin phagocytosis by macrophages and nonmacrophages during Wallerian degeneration. Microsc Res Tech 57:541-547.

Hofer M, Pagliusi SR, Hohn A, Leibrock J, Barde YA (1990) Regional distribution of brain-derived neurotrophic factor mRNA in the adult mouse brain. EMBO J 9:2459-2464.

Inserra MM, Bloch DA, Terris DJ (1998) Functional indices for sciatic, peroneal, and posterior tibial nerve lesions in the mouse. Microsurgery 18:119-124.

Kermani P, Hempstead B (2007) Brain-derived neurotrophic factor: a newly described mediator of angiogenesis. Trends Cardiovasc Med 17:140-143.

Klagsbrun M, Eichmann A (2005) A role for axon guidance receptors and ligands in blood vessel development and tumor angiogenesis. Cytokine Growth Factor Rev 16:535-548.

Kubota A, Suzuki K (2000) Effect of liposome-mediated macrophage depletion on Schwann cell proliferation during Wallerian degeneration. J Neurotrauma 17:789-798.

Lacroix S, Tuszynski MH (2000) Neurotrophic factors and gene therapy in spinal cord injury. Neurorehabil Neural Repair 14:265-275.

Lacroix S, Chang L, Rose-John S, Tuszynski MH (2002) Delivery of hyperIL-6 to the injured spinal cord increases neutrophil and macrophage infiltration and inhibits axonal growth. J Comp Neurol 454:213-228.

Lindholm D, Heumann R, Meyer M, Thoenen H (1987) Interleukin-1 regulates synthesis of nerve growth factor in non-neuronal cells of rat sciatic nerve. Nature 330:658-659.

Liu BP, Cafferty WB, Budel SO, Strittmatter SM (2006) Extracellular regulators of axonal growth in the adult central nervous system. Philos Trans R Soc Lond B Biol Sci 361:1593-1610.

Lykissas MG, Batistatou AK, Charalabopoulos KA, Beris AE (2007) The role of neurotrophins in axonal growth, guidance, and regeneration. Curr Neurovasc Res 4:143-151.

Ma M, Wei T, Boring L, Charo IF, Ransohoff RM, Jakeman LB (2002) Monocyte recruitment and myelin removal are delayed following spinal cord injury in mice with CCR2 chemokine receptor deletion. J Neurosci Res 68:691-702.

Maisonpierre PC, Belluscio L, Friedman B, Alderson RF, Wiegand SJ, Furth ME, Lindsay RM, Yancopoulos GD (1990) NT-3, BDNF, and NGF in the developing rat nervous system: parallel as well as reciprocal patterns of expression. Neuron 5:501-509.

Morrissey TK, Kleitman N, Bunge RP (1991) Isolation and functional characterization of Schwann cells derived from adult peripheral nerve. J Neurosci 11:2433-2442.

Nahrendorf M, Swirski FK, Aikawa E, Stangenberg L, Wurdinger T, Figueiredo JL, Libby P, Weissleder R, Pittet MJ (2007) The healing myocardium sequentially mobilizes two monocyte subsets with divergent and complementary functions. J Exp Med 204:3037-3047.

Pineau I, Lacroix S (2007) Proinflammatory cytokine synthesis in the injured mouse spinal cord: multiphasic expression pattern and identification of the cell types involved. J Comp Neurol 500:267-285.

Pineau I, Barrette B, Vallières N, Lacroix S (2006) A novel method for multiple labeling combining in situ hybridization with immunofluorescence. J Histochem Cytochem 54:1303-1313.

Plunet W, Kwon BK, Tetzlaff W (2002) Promoting axonal regeneration in the central nervous system by enhancing the cell body response to axotomy. J Neurosci Res 68:1-6.

Popovich PG, Guan Z, Wei P, Huitinga I, van Rooijen N, Stokes BT (1999) Depletion of hematogenous macrophages promotes partial hindlimb recovery and neuroanatomical repair after experimental spinal cord injury. Exp Neurol 158:351-365.

Ramon y Cajal S (1991) Cajal's degeneration and regeneration of the nervous system. New York: Oxford UP. 
Rapalino O, Lazarov-Spiegler O, Agranov E, Velan GJ, Yoles E, Fraidakis M, Solomon A, Gepstein R, Katz A, Belkin M, Hadani M, Schwartz M (1998) Implantation of stimulated homologous macrophages results in partial recovery of paraplegic rats. Nat Med 4:814-821.

Reichert F, Saada A, Rotshenker S (1994) Peripheral nerve injury induces Schwann cells to express two macrophage phenotypes: phagocytosis and the galactose-specific lectin MAC-2. J Neurosci 14:3231-3245.

Saada A, Reichert F, Rotshenker S (1996) Granulocyte macrophage colony stimulating factor produced in lesioned peripheral nerves induces the up-regulation of cell surface expression of MAC-2 by macrophages and Schwann cells. J Cell Biol 133:159-167.

Schwartz M, Yoles E (2006) Immune-based therapy for spinal cord repair: autologous macrophages and beyond. J Neurotrauma 23:360-370.

Stoll G, Griffin JW, Li CY, Trapp BD (1989) Wallerian degeneration in the peripheral nervous system: participation of both Schwann cells and macrophages in myelin degradation. J Neurocytol 18:671-683.
Terenghi G (1999) Peripheral nerve regeneration and neurotrophic factors. J Anat 194:1-14.

Vallières N, Berard JL, David S, Lacroix S (2006) Systemic injections of lipopolysaccharide accelerates myelin phagocytosis during Wallerian degeneration in the injured mouse spinal cord. Glia 53:103-113.

Weidner N, Blesch A, Grill RJ, Tuszynski MH (1999) Nerve growth factorhypersecreting Schwann cell grafts augment and guide spinal cord axonal growth and remyelinate central nervous system axons in a phenotypically appropriate manner that correlates with expression of L1. J Comp Neurol 413:495-506.

Yiu G, He Z (2006) Glial inhibition of CNS axon regeneration. Nat Rev Neurosci 7:617-627.

Zuo Y, Lubischer JL, Kang H, Tian L, Mikesh M, Marks A, Scofield VL, Maika S, Newman C, Krieg P, Thompson WJ (2004) Fluorescent proteins expressed in mouse transgenic lines mark subsets of glia, neurons, macrophages, and dendritic cells for vital examination. J Neurosci 24:10999-11009. 